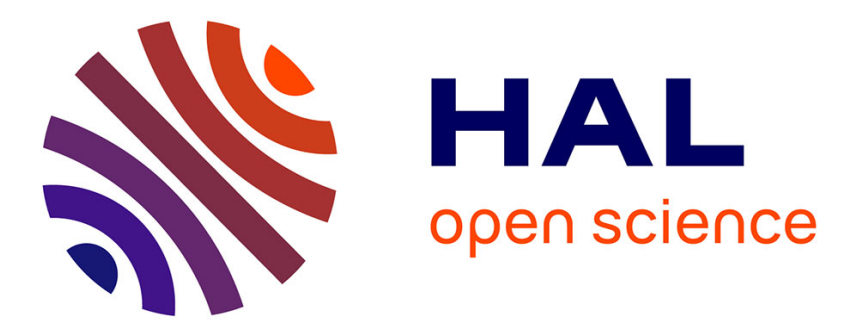

\title{
Organic complexation of rare earth elements in natural waters: evaluating model calculations from ultrafiltration data
}

Olivier Pourret, Mélanie Davranche, Gérard Gruau, Aline Dia

\section{- To cite this version:}

Olivier Pourret, Mélanie Davranche, Gérard Gruau, Aline Dia. Organic complexation of rare earth elements in natural waters: evaluating model calculations from ultrafiltration data. Geochimica et Cosmochimica Acta, 2007, 71 (11), pp.2718-2735. 10.1016/j.gca.2007.04.001 • hal-02136387

\section{HAL Id: hal-02136387 \\ https://hal.science/hal-02136387}

Submitted on 22 May 2019

HAL is a multi-disciplinary open access archive for the deposit and dissemination of scientific research documents, whether they are published or not. The documents may come from teaching and research institutions in France or abroad, or from public or private research centers.
L'archive ouverte pluridisciplinaire HAL, est destinée au dépôt et à la diffusion de documents scientifiques de niveau recherche, publiés ou non, émanant des établissements d'enseignement et de recherche français ou étrangers, des laboratoires publics ou privés. 


\title{
ORGANIC COMPLEXATION OF RARE EARTH ELEMENTS IN NATURAL WATERS: EVALUATING MODEL CALCULATIONS FROM ULTRAFILTRATION DATA
}

\author{
Running head: Organic complexation of REE in natural waters \\ Olivier Pourret*, Mélanie Davranche, Gérard Gruau and Aline Dia \\ CAREN, Géosciences Rennes, UMR CNRS 6118, Campus de Beaulieu \\ 35042 RENNES Cedex, France
}

Keywords: Rare earth elements, dissolved organic matter, speciation modelling, natural waters, ultrafiltration

*Author to whom correspondence should be addressed(olivier.pourret@univ-rennes1.fr). 
Abstract - The Stockholm Humic Model (SHM) and Humic Ion-Binding Models V and VI were compared for their ability to predict the role of dissolved organic matter (DOM) in the speciation of rare earth elements (REE) in natural waters. Unlike Models V and VI, SHM is part of a speciation code that also allows us to consider dissolution/precipitation, sorption/desorption and oxidation/reduction reactions. In this context, it is particularly interesting to test the performance of SHM. The REE specific equilibrium constants required by the speciation models were estimated using linear free-energy relationships (LFER) between the first hydrolysis constants and the stability constants for REE complexation with lactic and acetic acid. Three datasets were used for the purpose of comparison: (i) World Average River Water (Dissolved Organic Carbon $($ DOC $\left.)=5 \mathrm{mg} \mathrm{L}^{-1}\right)$, previously investigated using Model $\mathrm{V}$, was reinvestigated using SHM and Model VI; (ii) two natural organic-rich waters (DOC $=18-24 \mathrm{mg} \mathrm{L}^{-1}$ ), whose REE speciation has already been determined with both Model V and ultrafiltration studies, were also reinvestigated using SHM and Model VI; finally, (iii) new ultrafiltration experiments were carried out on samples of circumneutral- $\mathrm{pH}(\mathrm{pH}=6.2-7.1)$, organic-rich $\left(\mathrm{DOC}=7-20 \mathrm{mg} \mathrm{L}^{-1}\right)$ groundwaters from the Kervidy-Naizin and Petit-Hermitage catchments, western France. The results were then compared with speciation predictions provided by Model VI and SHM, successively. When applied to World Average River Water, both Model VI and SHM yield comparable results, confirming the earlier finding that a large fraction of the dissolved REE in rivers occurs as organic complexes This implies that the two models are equally valid for calculating REE speciation in low-DOC waters at circumneutral-pH. The two models also successfully reproduced ultrafiltration results obtained for DOC-rich acidic groundwaters and river waters. By contrast, the two models yielded different results when compared to newly obtained ultrafiltration results for DOC-rich (DOC $>7 \mathrm{mg} \mathrm{L}^{-1}$ ) groundwaters at circumneutral-pH, with Model VI predictions being closer to the ultrafiltration data than SHM. Sensitivity analysis indicates that the "active DOM parameter" (i.e., the proportion of DOC that can effectively complex with REE) is a key parameter for both Model VI and SHM. However, a survey of 
ultrafiltration results allows the "active DOM parameter" to be precisely determined for the newly ultrafiltered waters studied here. Thus, the observed discrepancy between SHM predictions and ultrafiltration results cannot be explained by the use of inappropriate "active DOM parameter" values in this model. Save this unexplained discrepancy, the results presented in this study demonstrate that both Model VI and SHM can provide reliable estimates of REE speciation in organic-rich waters. However, it is essential to know the proportion of DOM that can actively complex REE before running these two speciation models. 


\section{INTRODUCTION}

The aquatic geochemistry of rare earth elements (REE) has been the subject of numerous studies over the past two decades (Elderfield and Greaves, 1982; De Baar et al., 1988; Elderfield et al., 1990; De Baar et al., 1991; Smedley, 1991; Gosselin et al., 1992; Sholkovitz, 1995; Byrne and Sholkovitz, 1996; Johannesson et al., 1997; 2000; Johannesson and Hendry, 2000; Janssen and Verweij, 2003; Nelson et al., 2004). However, it is difficult to assess the extent to which REE patterns in natural waters are controlled by the source rocks (Johannesson et al., 1999; Dia et al., 2000; Aubert et al., 2001). Processes such as REE complexation by inorganic ligands, or REE adsorption onto solid mineral phases, can fractionate the REE (e.g., Johannesson et al., 1999; Coppin et al., 2002). There is also some evidence that REE adsorption onto Fe- and Mnoxides may lead to negative Ce anomalies in waters due to the oxidative scavenging of Ce onto these metallic oxides (Viers et al., 1997; Dupré et al., 1999; Dia et al., 2000; Davranche et al., 2004; Gruau et al., 2004; Davranche et al., 2005). Above all, REE complexation with natural organic ligands may be of prime importance in controlling REE fractionation in natural waters, as inferred from recent ultrafiltration and electrochemical studies of organic-rich waters (Tanizaki et al., 1992; Viers et al., 1997; Dupré et al., 1999; Dia et al., 2000; Ingri et al., 2000; Johannesson et al., 2004).

Consequently, it is essential to develop models to predict the complexation of REE with dissolved organic matter (DOM). For that purpose, we require REE binding constants for REEproton exchange with humic matter (HM). These constants can be experimentally determined, either for individual REE (e.g., Bidoglio et al., 1991; Moulin et al., 1992; Lead et al., 1998; Lippold et al., 2005) or for the whole REE series (Yamamoto et al., 2005; Sonke and Salters, 2006; Yamamoto et al., 2006). However, experimentally determined REE constants may be difficult to use because of differences in the $\mathrm{pH}$ and/or ionic strength conditions of the experiments (Bidoglio et al., 1991; Moulin et al., 1992; Lead et al., 1998; Lippold et al., 2005) or 
due to differences in the REE/HM ratio of the experimental solutions (Yamamoto et al., 2005; Sonke and Salters, 2006). An indirect method is to estimate the required Lanthanide-humic (LnHM) constants using the Linear Free Energy Relationships (LFER) existing between metalHM complexation and the stability constants for metal-lactic and metal-acetic acid complexation. These LnHM values can then be put into thermodynamic models aimed at predicting metal complexation with HM. The ability of the models to predict REE complexation with DOM can then be established by comparing model results with ultrafiltration data. The most successful attempt along these lines was made by Tang and Johannesson (2003), who applied the indirect method to test the ability of the well-known metal-HM speciation code Humic Ion-Binding Model V (Tipping, 1994) to predict REE complexation with DOM. Comparisons between model predictions and ultrafiltration results for six natural water samples were then used by these authors (op. cit.) to validate both the estimated LnHM and the model. Applying Model V to World Average River Water, Tang and Johannesson (2003) predicted that LnHM complexes are the principal carriers of REE in the dissolved (i.e., $<0.2 \mu \mathrm{m}$ ) fraction of river waters.

However, Model $\mathrm{V}$ is exclusively a speciation model that does not take account of other reactions (i.e., dissolution/precipitation, adsorption/desorption, oxidation/reduction) that are also important in controlling the REE distribution in waters. In this study, we test the ability of the Stockholm Humic Model (SHM) to predict REE complexation by HM (Gustafsson, 2001a; Gustafsson et al., 2003). This model was selected because it is part of a full chemical equilibrium model that allows modelling of all the above reactions (Visual MINTEQ; Gustafsson, 2001b). The aim of our study is also to compare SHM with Model VI, which is the latest version of the Humic Ion Binding Model (Tipping, 1998). REE constants were estimated using the above described indirect LFER method. For purposes of comparison, we used the following three-step approach: firstly, World Average River Water, previously investigated using Model V by Tang and Johannesson (2003), was reinvestigated successively using Model VI and SHM. Secondly, we used both SHM and Model VI to reinvestigate two of the six ultrafiltered organic-rich natural 
waters used by Tang and Johannesson (2003) to validate Model V. Finally, new ultrafiltration experiments were conducted using organic-rich (Dissolved Organic Carbon (DOC) 7-20 mg L ${ }^{-1}$ ) groundwaters with circumneutral-pH $(\mathrm{pH}=6.2-7.1)$ from the Kervidy-Naizin and PetitHermitage catchments, western France, and the results were compared with predictions from Model VI and SHM . Hence, the present study is also a new step in assessing the ability of the Humic Ion Binding Model to predict REE complexation by organic matter in natural waters. So far, this model has been compared to only a limited number of ultrafiltration results (Tang and Johannesson, 2003).

\section{MATERIALS AND METHODS}

In this paper, we use the term organic matter-bound REE solution complex in the same way as in Tang and Johannesson (2003), namely, to include REE complexed to both low- and highmolecular weight (MW) organic matter.

\subsection{Description of models}

Humic Ion-Binding Model VI (here referred to as Model VI) is the latest version of a model developed by Tipping and co-workers in the early 1990s (Tipping and Hurley, 1992; Tipping, 1994; Tipping, 1998). Model VI is a discrete site-electrostatic model for proton and metal ion interactions with fulvic (FA) and humic (HA) acids. The thermodynamic basis of the model has been presented and discussed in detail elsewhere (e.g., Tipping, 1998). Briefly, the model assumes that proton and metal complexation by organic matter involve two types of discrete sites

(Type A and Type B) that have separate intrinsic binding constants for metals: $\log \mathrm{K}_{\mathrm{MA}}$ and $\log$ $\mathrm{K}_{\mathrm{MB}}$. By considering results from many datasets, we obtain a universal average value of $\Delta \mathrm{LK}_{1}$, and can establish a correlation between $\log \mathrm{K}_{\mathrm{MB}}$ and $\log \mathrm{K}_{\mathrm{MA}}$ (Tipping, 1998). Thus, we only require one single adjustable parameter $\left(\log \mathrm{K}_{\mathrm{MA}}\right)$ to fully describe metal binding in Model VI. 
The parameters necessary to run the model are presented in Table EA1-Electronic Annex (based on Tipping, 1998). As shown by Tipping (1998) and Tipping et al. (2002), updating Model V to Model VI leads in many cases to an overall improvement of the predictive power of the model.

The Stockholm Humic Model (SHM) is an integral part of the chemical equilibrium model Visual MINTEQ (Gustafsson, 2001b), which enables modelling of solution speciation along with adsorption/desorption, dissolution/precipitation and redox reactions. The principles of SHM have been fully presented and discussed elsewhere by Gustafsson (2001a) and Gustafsson et al. (2003). Where applicable, Gustafsson (2001a) gave the same symbols to denote SHM parameters as those used for corresponding parameters in Models VI, for sake of consistency. SHM is a discrete-ligand model in which the FA and HA are assumed to have eight proton-binding sites with distinct acid-base characteristics. In this model, seven adjustable parameters $\left(\mathrm{n}_{\mathrm{A}}, \mathrm{n}_{\mathrm{B}}, \log \mathrm{K}_{\mathrm{A}}\right.$, $\log \mathrm{K}_{\mathrm{B}}, \Delta \mathrm{pK} \mathrm{K}_{\mathrm{A}}, \Delta \mathrm{pK_{ \textrm {B } }}$ and $\mathrm{g}_{\mathrm{f}}$ ) are required to describe the proton dissociation reaction. Table EA2Electronic Annex lists the fixed values that Gustafsson (2001a) derived for these seven parameters for FA and HA. In the present study, we select the generic values for these parameters listed in the "shmgeneric.mdb" database, since they are average values obtained from a large number of aquatic FA and HA samples (Gustafsson, 2001b). Three parameters are normally required with SHM to model the complexation of metals with organic matter, i.e., the monodentate complexation constant $\mathrm{K}_{\mathrm{Mm}}$, the bidentate complexation constant $\mathrm{K}_{\mathrm{Mb}}$, and the $\Delta \mathrm{LK}_{2}$ parameter, which determines the degree of binding site heterogeneity. Gustafsson (2001a) demonstrated that trivalent cation (e.g., $\mathrm{Al}$ ) organic complexation is better fitted if only bidentate binding is involved. Therefore, in practice, only a single adjustable parameter $\left(\log \mathrm{K}_{\mathrm{Mb}}\right)$ is necessary to fully describe trivalent metal complexation by HM in natural waters (Gustafsson, 2001b).

However, results from both SHM and Model VI depend on the values of the $\Delta \mathrm{LK}_{2}$ parameter (i.e., the distribution term that modifies the strengths of complexation sites) which is input in models. Because SHM and Model VI are different in a number of respects, a $\Delta \mathrm{LK}_{2}$ value adopted 
from Model VI cannot be expected to yield similar good fits for SHM. In the following we use the $\Delta \mathrm{LK}_{2}$ values which were optimized by fitting published datasets (Milne et al., 2003) for SHM (namely 1.3; Gustafsson, 2001b) or from a correlation with the equilibrium constant for complexation of the metal with $\mathrm{NH}_{3}$ for Model VI (0.29; Lead et al., 1998; Tipping, 1998). The $\Delta \mathrm{LK}_{2}$ values are constrained to be identical for the whole REE series as REE are known for their chemical similarity.

\subsection{Estimating constant values for the REE}

As pointed out in the introduction, we used the LFER method to estimate the specific binding constants necessary to run Model VI and SHM. The LFER method is based on Tipping's observation (Tipping, 1994; Tipping, 1998) that a LFER exists between $\log \mathrm{K}_{\mathrm{MA}}$ and $\log \mathrm{K}$ for metal-lactic acid (LA) and metal-acetic acid (AA) complexation. Moreover, since this author (op. cit.) also notes a relation between $\log \mathrm{K}_{\mathrm{MA}}$ and the first hydrolysis $(\mathrm{OH})$ constants for metal (denoted here as $\log \mathrm{K}(\mathrm{AA}), \log \mathrm{K}(\mathrm{LA})$ and $\log \mathrm{K}(\mathrm{OH})$ ), the LFER can be used to estimate $\log$ $\mathrm{K}_{\mathrm{MA}}(\mathrm{REE})$ from published values of $\log \mathrm{K}(\mathrm{REE}-\mathrm{AA})$, log K(REE-LA) and log K(REE-OH). The same approach can be used to estimate $\log \mathrm{K}_{\mathrm{Mb}}(\mathrm{REE})$, the only difference being the assumption that the metal complexing capacity of one ligand with two functional groups (as expressed by $\mathrm{K}_{\mathrm{Mb}}$ ) is similar to the metal complexing capacity of two ligands carrying only one functional group each (as expressed by $\mathrm{K}_{2}$ ).

Tables 1 and 2 list $\log \mathrm{K}_{\mathrm{MA}}$ and $\log \mathrm{K}_{\mathrm{Mb}}$ values describing the complexation of numerous metals with HA and FA (data from Tipping, 1998, and Gustafsson, 2001b), along with published

$\log \mathrm{K}(\mathrm{AA}), \log \mathrm{K}(\mathrm{LA}), \log \mathrm{K}(\mathrm{OH}), \log \mathrm{K}_{2}(\mathrm{AA}), \log \mathrm{K}_{2}(\mathrm{LA})$ and $\log \mathrm{K}_{2}(\mathrm{OH})$ for the same metals (values from NIST Database; Martell and Smith, 1998). Studentized residuals (i.e., the residual divided by its standard deviation; Ramsey, 1969) were used to detect and remove outlier cations (i.e., $\mathrm{Cd}$ and $\mathrm{Th}$ ). The values of $\log \mathrm{K}_{\mathrm{MA}}$ and $\log \mathrm{K}_{\mathrm{Mb}}$ show good linear correlations with their 
hydrolysis constants, as well as the constants for LA and AA complexation (Figs. 1 and 2). The linear regression curves and correlation coefficients describing these relationships are as follows:

$$
\begin{array}{ll}
\log \mathrm{K}_{\mathrm{MA}}(\mathrm{HA})=0.76 \log \mathrm{K}(\mathrm{LA})-0.21 & \mathrm{R}^{2}=0.80 \\
\log \mathrm{K}_{\mathrm{MA}}(\mathrm{FA})=0.52 \log \mathrm{K}(\mathrm{LA})+0.58 & \mathrm{R}^{2}=0.78 \\
\log \mathrm{K}_{\mathrm{MA}}(\mathrm{HA})=1.03 \log \mathrm{K}(\mathrm{AA})-0.43 & \mathrm{R}^{2}=0.80 \\
\log \mathrm{K}_{\mathrm{MA}}(\mathrm{FA})=0.75 \log \mathrm{K}(\mathrm{AA})+0.36 & \mathrm{R}^{2}=0.87 \\
\log \mathrm{K}_{\mathrm{MA}}(\mathrm{HA})=0.24 \log \mathrm{K}(\mathrm{OH})+0.32 & \mathrm{R}^{2}=0.78 \\
\log \mathrm{K}_{\mathrm{MA}}(\mathrm{FA})=0.17 \log \mathrm{K}(\mathrm{OH})+0.91 & \mathrm{R}^{2}=0.83 \\
\log \mathrm{K}_{\mathrm{Mb}}=1.89 \log \mathrm{K}_{2}(\mathrm{LA})-15.13 & \mathrm{R}^{2}=0.81 \\
\log \mathrm{K}_{\mathrm{Mb}}=1.49 \log \mathrm{K}_{2}(\mathrm{AA})-11.80 & \mathrm{R}^{2}=0.82 \\
\log \mathrm{K}_{\mathrm{Mb}}=0.57 \log \mathrm{K}_{2}(\mathrm{OH})-13.86 & \mathrm{R}^{2}=0.73
\end{array}
$$

These equations were subsequently employed to estimate $\log \mathrm{K}_{\mathrm{MA}}$ (Table 3) and $\log \mathrm{K}_{\mathrm{Mb}}$ (Table 4), using the $\log \mathrm{K}(\mathrm{AA}), \log \mathrm{K}(\mathrm{LA}), \log \mathrm{K}(\mathrm{OH}), \log \mathrm{K}_{2}(\mathrm{AA}), \log \mathrm{K}_{2}(\mathrm{LA})$ and $\log \mathrm{K}_{2}(\mathrm{OH})$ values listed for REE in the NIST Database (Martell and Smith, 1998; except log K(OH) listed in Klungness and Byrne, 2000; Figs. 1 and 2). However, as shown by Tables 3 and 4, the estimated values of $\log \mathrm{K}_{\mathrm{MA}}$ and $\log \mathrm{K}_{\mathrm{Mb}}$ vary depending on the equation used. To establish which sets of estimated values are more appropriate, we used the method of Tang and Johannesson (2003) to compare them with $\log \mathrm{K}_{\mathrm{MA}}$ and $\log \mathrm{K}_{\mathrm{Mb}}$, which were determined by fitting Model VI and SHM to the available experimental data (Tipping 1998; Gustafsson, 2001b). For purposes of comparison, we only considered "best-fit" values of $\log \mathrm{K}_{\mathrm{MA}}$ and $\log \mathrm{K}_{\mathrm{Mb}}$ (rms errors $<0.1$ ), which limits the comparison solely to Eu and Dy (Tipping, 1998; Lead et al., 1998; Gustafsson, 2001b). It is clear that the $\log \mathrm{K}_{\mathrm{MA}}$ values are too low when estimated from the LFER based on first hydrolysis constants (e.g., $\log \mathrm{K}_{\mathrm{MA}}=1.79$ for Eu-HA complexation using Eqn. 5, as against 2.10 using model fits). The same is true for Dy complexation by HA and FA (e.g., $\log \mathrm{K}_{\mathrm{MA}}=1.83$ 
for Dy-HA complexation as obtained from Eqn. 5, as against 2.9 using model fits). However, this does apply to the $\log \mathrm{K}_{\mathrm{MA}}$ values estimated from Eqns. 1 to 4 , where estimated values for Eu and Dy are close to the fitted experimental data (e.g., 2.47 and 2.44 for Eu-FA complexation using Eqn. 2 and 4, respectively, as against 2.36 from model fits). The $\log \mathrm{K}_{\mathrm{MA}}$ estimates derived from the first hydrolysis constant LFER appear much too low. Whatever the reason, the observed discrepancy between estimates derived from Eqn. 5 and 6 and fits of experimental data leads us to eliminate these two equations from our procedure for estimating constants.

However, $\log \mathrm{K}_{\mathrm{MA}}$ values estimated from Eqn. 1 to 4 are quite different for the HREE (on average, standard deviation are as high as 0.41 ). Recently published experimental results for REE complexation with FA and HA (Yamamoto et al., 2005; 2006) suggest that the log K values for REE complexation with HM should vary across the REE series in an analogous way to the $\log \mathrm{K}$ values for AA. Moreover, Wood (1993) pointed out that AA likely represents a model system for simple carboxylic sites on more complex organic matter, such as HM. Carboxylic groups could thus be the major sites by which REE are bound to HM (Yamamoto et al., 2005; 2006).

$\log \mathrm{K}_{\mathrm{Mb}}$ values estimated using Eqns. 7, 8 and 9 strongly differ from one another: by approximately two orders of magnitude for the LREE and by four orders of magnitude for the HREE (Table 4). As with the $\log \mathrm{K}_{\mathrm{MA}}$ values, $\log \mathrm{K}_{\mathrm{Mb}}$ can be estimated by comparing the values obtained for Eu with the $\log \mathrm{K}_{\mathrm{Mb}}$ values determined by fitting SHM to Eu experimental results (Gustafsson, 2001b). By using the second hydrolysis constants, we obtain a log $K_{M b}$ value of 7.36 for Eu that is dramatically low compared to -4.7 from the model fit (see Gustafsson, 2001b). By contrast, the $\log \mathrm{K}_{\mathrm{Mb}}$ values estimated for Eu using Eqns. 7 and 8 (-4.15 and -4.79 from Eqn. 7 and 8, respectively) are closer to the fitted experimental data for this REE than the value of 4.65 derived from the model fit (Gustafsson, 2001b). However, as with the log $\mathrm{K}_{\mathrm{MA}}$ values, we note that the $\log \mathrm{K}_{\mathrm{Mb}}$ values estimated using Eqns. 7 and 8 agree better with one another for the LREE and MREE than for the HREE (the standard deviation varies up to 1.89 for the latter). 
Bearing in mind that metal complexation with AA is probably a better analogy for REE complexation with HM than metal complexation with LA (see discussion above), in the following, we adopt the $\log \mathrm{K}_{\mathrm{Mb}}$ values estimated from Eqn. 8. To conclude, we should point out that, due to the smaller amount of experimental data, the AA LFER used to estimate $\log \mathrm{K}_{\mathrm{Mb}}$ values is less well constrained than the AA LFER used to estimate log $\mathrm{K}_{\mathrm{MA}}$. Thus, we can expect that modelling results derived from SHM are likely to be accompanied by larger uncertainties than Model VI predictions.

\section{COMPARING THE PREDICTIVE ABILITY OF SHM AND MODELS V AND VI}

Speciation calculations were performed using the computer programs WHAM 6 (Version 6.0.13) for Model VI, and Visual MINTEQ (Version 2.40) for SHM. Each model was modified by building a database that included our adopted $\log \mathrm{K}_{\mathrm{MA}}$ and $\log \mathrm{K}_{\mathrm{Mb}}$ values for $\mathrm{REE}$ complexation with $\mathrm{HM}$, along with well-accepted infinite-dilution $\left(25^{\circ} \mathrm{C}\right)$ stability constants for REE inorganic complexes (hydroxide, sulphate and carbonate; Klungness and Byrne, 2000; Luo and Byrne, 2004; Schijf and Byrne, 2004). Up-to-date, default values of log $\mathrm{K}_{\mathrm{MA}}, \log \mathrm{K}_{\mathrm{Mm}}$ and

$\log \mathrm{K}_{\mathrm{Mb}}$ were used for competing cations (Tipping, 1998; Gustafsson, 2001b). As oxyhydroxide precipitation reactions can not be modelled by Model VI, they were not considered in SHM modelling. In our simulations, we do not take into account the binding of the first hydrolysis product to HM. This choice is supported by the fact that (i) all the tested waters have $\mathrm{pH}<7$; yet, it is well established that the proportion of $\mathrm{Ln}-\mathrm{OH}$ complexes and thus $\mathrm{Ln}-\mathrm{OH}-\mathrm{HM}$ complexes may become important only for water having $\mathrm{pH}>8$ (Maes et al., 1988); (ii) even for alkaline waters, recent model calculations show that REE speciation can be reasonably well captured by only considering $\mathrm{Ln}^{3+}$ complexation with HM (Pourret et al., 2007).

In the speciation calculations presented here for World Average River Water, and Mengong and Mar2 samples, we follow the same assumptions as Tang and Johannesson (2003), i.e., (i) the 
DOM/DOC ratio of all samples is taken to be equal to 2; (ii) $50 \%$ of the DOM is considered to consist of HM able to complex the REE, the remaining 50\% comprising simple organic acids that cannot form REE complexes. Thus, the active-DOM/DOC ratio (referred to here as the "active DOM parameter") is taken as equal to unity for these samples.

\subsection{World Average River Water}

We applied the same DOC $\left(5 \mathrm{mg} \mathrm{L}^{-1}\right)$, major ion, Fe and $\mathrm{Al}$ concentrations as those used by Tang and Johannesson (2003) in their earlier modelling of REE speciation in World Average River Water (see Table 11 in Tang and Johannesson, 2003). We also followed their assumption that $80 \%$ of the HM in this sample is present as FA and $20 \%$ as HA. Thus, the DOM content of World Average River Water is $10 \mathrm{mg} \mathrm{L}^{-1}$, of which only $5 \mathrm{mg} \mathrm{L}^{-1}$ consist of $\mathrm{HM}$ able to complex with the REE, with $4 \mathrm{mg} \mathrm{L}^{-1}(80 \%)$ present as FA, and $1 \mathrm{mg} \mathrm{L}^{-1}(20 \%)$ as HA. Finally, because $\mathrm{pH}$ has a crucial influence on REE speciation, we also investigated the REE speciation of World Average River Water as a function of varying $\mathrm{pH}$, while keeping the major solute composition constant (except carbonate alkalinity varying as a function of $\mathrm{pH}$ ). Except for the slight modification of complexation constants, our model running procedure is thus entirely comparable to that used by Tang and Johannesson (2003).

The new modelling results are shown for La, Eu, and Lu in Figs. 3 (Model VI) and 4 (SHM), respectively. Model VI calculations predict that REE occur as free species $\left(\mathrm{Ln}^{3+}\right)$ and sulphate complexes $\left(\mathrm{LnSO}_{4}{ }^{+}\right)$at acidic $\mathrm{pH}$, and mainly as carbonate complexes $\left(\mathrm{LnCO}_{3}{ }^{+}\right.$and $\left.\mathrm{Ln}\left(\mathrm{CO}_{3}\right)^{2-}\right)$ at alkaline $\mathrm{pH}$ (Fig. 3). Based on these results, we also predict that, at circumneutral-pH conditions, the REE predominantly (i.e., >50\%) occur in solution complexed with HM. More precisely, Model VI predicts that $>50 \%$ of the LREE (e.g., La) occur in solution as organic complexes in the $\mathrm{pH}$ range between 5.2 and 9.5. For the MREE (e.g., Eu), the prediction is that $>50 \%$ of the MREE occur as HM complexes in the $\mathrm{pH}$ range between 4.3 and 9.5. Finally, Model 
VI predicts that $>50 \%$ of the HREE (e.g., Lu) occur as HM complexes in the $\mathrm{pH}$ range between 5.4 and 7. Another important result of the model is that the $\mathrm{pH}$ value at which the proportion of LnHM complexes reaches a maximum decreases across the REE series, from $\mathrm{La}(\mathrm{pH}=7)$ to $\mathrm{Lu}$ $(\mathrm{pH}=6)$. Also, model results indicate that the proportion of REE forming HM complexes is higher for the LREE and MREE (up to 95\% at $\mathrm{pH} 7$ ) than for the HREE (maximum of $60 \%$ at $\mathrm{pH}$ 6). All these features are consistent with Model V predictions reported previously by Tang and Johannesson (2003). The only noticeable difference is that Model VI calculates significantly higher proportions of REE complexed with organic matter under high $\mathrm{pH}$ conditions: for example, Model VI predicts LaHM $\sim 60 \%$ at pH 9, whereas Model V predicts only $10 \%$ of LaHM complexes at this $\mathrm{pH}$ value.

As with Models V and VI, SHM predicts that the LREE and MREE occur predominantly (i.e., $>50 \%$ ) in solution as $\mathrm{HM}$ complexes at circumneutral $\mathrm{pH}$ conditions. By contrast, the prediction is lower for the HREE: maximum organic complexation $\sim 40 \%$, against $\sim 50 \%$ with Model VI. As with Models V and VI, the $\mathrm{pH}$ value at which maximum REE complexation is predicted to occur also regularly decreases across the REE series, from 7.8 for La to 6.6 for Lu. However, we note three important differences with the Models V and VI results: (i) the $\mathrm{pH}$ at which there is a maximum proportion or REE organic complexes is about $0.75 \mathrm{pH}$ unit higher with SHM (Fig. 4) than with Model VI (Fig. 3); (ii) the range of $\mathrm{pH}$ values over which LnHM complexes are the predominant REE species is wider with Model VI than with SHM (e.g., LaHM $>50 \%$ for a range of $4.3 \mathrm{pH}$ units with Model VI, as against only $3 \mathrm{pH}$ units with SHM; see Figs. 3 and 4); finally, (iii) the proportion of LnHM species calculated at alkaline $\mathrm{pH}$ is higher with Models VI (e.g. for $\mathrm{La}, \sim 50 \%$ at $\mathrm{pH} 9.5$; see Fig. 3) than with SHM (e.g. for $\mathrm{La}, \sim 40 \%$ at $\mathrm{pH}$ 9.5; see Fig. 4).

To sum up, predictions from Model VI and SHM confirm the two main conclusions proposed earlier by Tang and Johannesson (2003) from speciation modelling of World Average River Water, namely that (i) organic colloids are the principal REE carriers in the dissolved fraction 
(i.e., $<0.2 \mu \mathrm{m}$ ); and (ii) dissolved organic ligand complexes of the REE are at least as important as carbonate complexes. The results of Model VI and SHM are clearly consistent for circumneutral-pH river waters, at least in broad outline. However, on the basis of the modelled data alone, it is difficult to determine whether Models V and VI or SHM gives the most accurate description of REE speciation in river waters. Only experimental studies involving direct measurement of the REE speciation in circumneutral-pH rivers will be able to decide which model is in better agreement with reality; for example, whether the proportion of LuHM complexes in these rivers is $\geq 50 \%$ as predicted by Models V and VI, or only $\sim 40 \%$ as predicted by SHM.

\subsection{Mengong and Mar2 samples}

Mengong and Mar2 are two samples of organic-rich $\left(\mathrm{DOC}=23.8\right.$ and $\left.18.1 \mathrm{mg} \mathrm{L}^{-1}\right)$ acidic waters whose REE speciation was first investigated by ultrafiltration (Viers et al., 1997), and then modelled using Model V (Tang and Johannesson, 2003). Because the DOC of these waters is chiefly made up of the largest MW size fractions (Viers et al., 1997), Tang and Johannesson (2003) assumed that $85 \%$ of the DOC in these samples is composed of high MW HA, the remaining $15 \%$ containing low MW FA. The same assumption is used here. The values adopted for $\mathrm{pH}$ (Mengong $=4.6$ and Mar2 = 5.5), as well as the major solute, $\mathrm{DOC}, \mathrm{Fe}$ and $\mathrm{Al}$ concentrations, are those reported by Viers et al. (1997), being identical to the values used by Tang and Johannesson (2003). Table 5 lists the predicted proportions of LnHM complexes in these two water samples based on Model VI and SHM, as well as a comparison with the previous results obtained using Model V (Tang and Johannesson, 2003). Model VI predicts that between 46-90\% (Mengong) and >98\% (Mar2) of the REE occurring in the dissolved fraction (i.e., $<0.2$ $\mu \mathrm{m})$ of these samples occurs as organic complexes, the remainder of each REE occurring as free

species $\left(\mathrm{Ln}^{3+}\right)$. Table 5 shows a good agreement between the Model VI and Model V predictions, 
the only noticeable difference being the slightly lower proportion of HREE organic complexes obtained with Model VI for the more acidic Mengong sample (Table 5; see also Table 8 in Tang and Johannesson, 2003). This difference is likely explained by our choice to use the $\log \mathrm{K}_{\mathrm{MA}}$ values derived from the AA LFER rather than the $\log \mathrm{K}_{\mathrm{MA}}$ values, which are averages of the estimates obtained using both the AA and LA LFER as described in Tang and Johannesson (2003). As shown above in the case of the World Average River Water sample, this choice shifts the LnHM stability field slightly towards higher $\mathrm{pH}$ values (compare our Fig. 3 and Fig. 4 in Tang and Johannesson, 2003), thereby decreasing the proportion of REE complexed with organic matter in acidic waters as predicted by the Humic Ion Binding Model.

SHM results are consistent with the predictions of Model V and VI for Mar2, while also indicating a predominance of LnHM complexes in this sample. The predicted complexation proportions based on SHM are equivalent to those predicted by Models V and VI (i.e., between 90 and 99\% for SHM, compared with 98 and 100\% for Model VI and 87 and $96 \%$ for Model V depending on the REE; see Table 5). By contrast, the results for Mengong are different. Indeed, SHM predicts that HM complexes should account for only 34 to $71 \%$ of each REE in solution, whereas Models VI and V predict higher complexation proportions, namely: between 46 and 90\% (Table 5). For both the Mar2 and Mengong samples, the three tested models all indicate that the remainder of each REE occurs as free species $\left(\mathrm{Ln}^{3+}\right)$. By comparing the model predictions to the ultrafiltration results (Table 5), we can see that Model VI and SHM yield comparable agreement with ultrafiltration data for Mar2 sample (less than $10 \%$ difference). However, for the more acidic Mengong water sample, the difference between model predictions and ultrafiltration results is higher when using SHM compared with Models V and VI, i.e., between 27 and 62\%, as against between 10 and 52\% (Table 5).

In summary, we confirm the suggestion made earlier by Tang and Johannesson (2003) that the Humic Ion-Binding Model is reasonably good representation of REE speciation in acidic DOC-rich waters. The differences between our predictions and those reported in Tang and 
Johannesson (2003) further demonstrate the sensitivity of models to the values of the stability constants that are introduced. As regards SHM, the results presented above might suggest that this model is less accurate in predicting the speciation of the REE in low-pH, organic-rich natural waters. In the present study, however, we show that the ability of SHM to predict REE speciation in this type of water depends strongly on the value of the "active DOM parameter" that is introduced into the model. By changing this value to more appropriate values than those used by Tang and Johannesson (2003), we can drastically improve the agreement between SHM and Model VI predictions, and ultrafiltration data (see Discussion section).

\subsection{Kervidy-Naizin and Petit Hermitage groundwater samples}

\subsubsection{Ultrafiltration data}

To further test the ability of SHM and Model VI to predict REE complexation with organic matter, we performed new ultrafiltration experiments on four circumneutral $(\mathrm{pH}=6.2-7.1)$, organic-rich $\left(\mathrm{DOC}=7-20 \mathrm{mg} \mathrm{L}^{-1}\right)$ groundwater samples $(\mathrm{PF} 1, \mathrm{PF} 3, \mathrm{~F} 7$ and F14). The samples were collected from two wetlands located in the Kervidy-Naizin and Petit-Hermitage catchments, in western France. These groundwaters have already been intensively studied for their DOC and REE chemistry (Dia et al., 2000; Olivié-Lauquet et al., 2001; Gruau et al., 2004). Appendix 1 gives details on the ultrafiltration procedure and chemical analysis of these samples.

Table EA3-Electronic Annex presents the concentrations of major anions and cations, as well as major and trace cations (including REE) and DOC in the $0.2 \mu \mathrm{m}$ filtrates, along with alkalinity and $\mathrm{pH}$ data. Concentrations of $\mathrm{REE}, \mathrm{Fe}, \mathrm{Mn}$ and $\mathrm{DOC}$ in the three ultrafiltered fractions (i.e., $<30 \mathrm{kDa}(\mathrm{Da}=$ Dalton $),<10 \mathrm{kDa}$ and $<5 \mathrm{kDa})$ are presented in Table EA4-Electronic Annex (mean of two analyses). In Fig. 5, these results are plotted on REE (Fe) vs. DOC variation diagrams. 
Interpreting ultrafiltration data is not a trivial task and care must be taken to validate the speciation models before using this type of information. An inherent feature of ultrafiltration studies is the presence of mineral colloids (e.g., Fe and Mn oxyhydroxides) in the waters along with organic colloids. Some of these mineral colloids can be potentially strong competitors with organic matter for REE complexation (e.g., Fe oxyhydroxides; Bau, 1999; Dupré et al., 1999), and their presence may lead to an overestimation of the proportion of REE that are effectively complexed by HM. Thus, it is crucial to assess carefully whether the REE decrease associated with ultrafiltration of PF1, PF3, F7 and F14 waters (see Fig. 5) is accompanied solely by a decrease of the DOC content, or whether it is also correlated with a decrease in Fe concentration. It is clear that three of the four investigated water samples (i.e., PF1, F7 and F14) display a significant decrease in Fe content upon ultrafiltration (Fig. 5). However, the decrease in $\mathrm{Fe}$ content concerns only the $30 \mathrm{kDa}$ ultrafiltration step. After this step, the Fe content is equally very low in all four samples, resulting in a marked change in the slope of the linear relationships otherwise shown on the REE vs. DOC variation diagrams (Fig. 5). This behaviour is particularly well illustrated by sample PF1, where ca. $80 \%$ of the REE and $96 \%$ of the Fe, but only $9 \%$ of the DOC, are removed during the first ultrafiltration step. Moreover, the magnitude of the change in the slope of the REE-DOC linear relationship appears to be correlated with the Fe/ $\Sigma$ REE ratio of

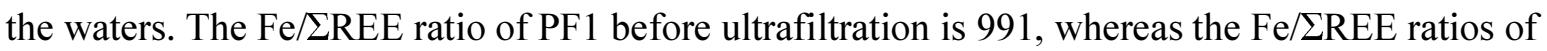
F7, F14 and PF3 are 984, 737 and 55, respectively. Such relationships strongly suggest that the "colloidal" REE budget of samples PF1, F7 and F14 is partly controlled by REE-bearing Fe colloids. The Fe-colloid/organic-colloid ratio in these samples decreases in following order: PF1 $>$ F7 > F14 >> PF3.

The REE colloidal pool of samples PF1, F7 and F14 was corrected for the contribution of the Fe-colloid fraction. The Fe colloid-free REE budget of these waters can be estimated by linearly extrapolating the relationship defined by the $<5 \mathrm{kDa},<10 \mathrm{kDa}$ and $<30 \mathrm{kDa}$ results to the DOC content of the $<0.2 \mu \mathrm{m}$ fraction (point A in Fig. 5). The linear correlation defined by the DOC 
and REE contents of the four ultrafiltered fractions of PF3 (i.e., the water sample clearly depleted in Fe colloid) suggests that the organic fractions should yield a linear correlation in the REE vs. DOC variation plots. This interpretation is supported by the fact that the REE vs. DOC correlations defined by the three Fe colloid-bearing waters (i.e., PF1, F7 and F14) yield a slope that decreases with decreasing Fe/REE ratio of the raw waters. This implies that the REE and DOC contents are linearly correlated in Fe-free waters. Another problem arises during ultrafiltration studies of organic-rich waters when there is a negative $y$-axis intercept for the REE vs. DOC correlation (Fig. 5). The likely interpretation for this is that (i) $100 \%$ of the REE present in the waters are bound to organic molecules and, more importantly (ii) the DOM is not composed solely of HM able to complex REE, but contains also a significant proportion of low MW organic molecules that do not complex these elements. In such waters, the key question is how to determine the amount of DOM that can complex the REE. In other words, we need to decide what value for the "active DOM parameter" should be introduced into the models. Considering the PF3 results, it is possible that this amount of active DOM could correspond to the $y=0$ intercept on the $x$-axis obtained by linearly extrapolating the REE vs. DOC relationships (points B in Fig. 5). In so doing, we assume that all the REE are bound to HM, which is consistent with previously published ultrafiltration data (Tanikazi et al., 1992; Sholkovitz, 1995; Ingri et al., 2000). This assumption also agrees with recent observations by Johannesson et al. (2004) that all of the "dissolved" La in organic-rich waters from a swamp in south-eastern Virginia is "complexed" with organic ligands.

In the following, we assume that (i) $100 \%$ of the REE occurring in PF1, PF3, F7 and F14 waters are bound to $\mathrm{HM}$; (ii) the REE remaining in the $<5 \mathrm{kDa}$ fraction are complexed with the low molecular FA; and (iii) the amount of REE complexed with the HA fraction corresponds to the REE content of point A minus the $<5 \mathrm{kDa}$ fraction. Table 6 reports the proportions of LnHA and LnFA complexes calculated in this way for the Kervidy-Naizin and Petit Hermitage groundwater samples. The average proportions of LnHA are lower for PF3 and F7 (65 and 76\%, 
respectively), but higher for PF1 and F14 (77 and 83\%, respectively). Using these results, we estimated the LnFA/LnHA ratios of the four ultrafiltered samples as 0.30 for PF1, 0.54 for PF3, 0.31 for F7 and 0.21 for F14 (Table 6). The above calculations are strongly dependent on the validity of the correction/estimation procedures used to remove the contribution of Fe colloids and calculate the FA/HA ratio of the waters. The validity of this approach is tested below, by comparing the "corrected/estimated" ultrafiltration data with the modelled results. If the results of this test are positive - i.e., there is convergence between the modelling and ultrafiltration results this confirms the ability of the models to predict LnHM speciation in the four investigated water samples, considering that the procedure for correction of the ultrafiltration data is independent of the modelling approach.

\subsubsection{REE speciation modelling}

The modelling of the Kervidy-Naizin and Petit Hermitage samples is treated differently from the samples of World Average River Water, Mengong and Mar2, since the amount of active DOM is not taken as equivalent to a common empirical value of $50 \%$ of the total DOM content, but equal to individual values calculated following the method described above. The active DOM fractions obtained in this way are as follows: $32 \%$ for PF1, 55\% for PF3, 53\% for $\mathrm{F} 7$ and $59 \%$ for F14. Using the ultrafiltration results, we also calculated the HA and FA contents necessary to run both models. The HA contents are assumed to be equal to two times the difference between the DOC contents of the $<0.2 \mu \mathrm{m}$ and $<5 \mathrm{kDa}$ fractions. For FA, we take the value as two times the difference between the DOC content of the $<5 \mathrm{kDa}$ fraction and that corresponding to point $\mathrm{B}$ in Fig. 5. Hence, we assume that 65, 76, 83 and 77\% and 35, 24, 17 and 23\% of HM is made up of FA and HA, respectively, in PF3, F7, F14 and PF1. Finally, we should bear in mind that the REE content introduced into the models corresponds to point A in Fig. 5 and not the total REE content of the sample. 
Table 6 presents the model results, which are compared with corrected ultrafiltration data. The "modelled" complexation proportions reported in Table 6 include the REE partitioning between the high MW HA fraction ( $>5 \mathrm{kDa})$ and the low MW FA fraction $(<5 \mathrm{kDa})$. Table 6 shows a good convergence between Model VI and ultrafiltration results. LnHM proportions calculated with Model VI are all higher than 97\%, indicating that this model also predicts that nearly all of the REE are complexed by HM in these samples. By contrast, the convergence is of poorer quality with SHM: LnHM proportions range from 43 to $100 \%$ depending on the samples, while the remainder of the REE occurs as carbonate, sulphate or free ion species (data not

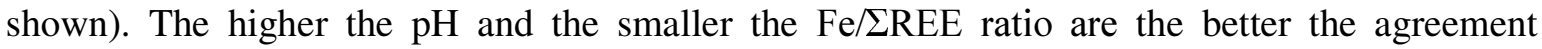
between SHM prediction and ultrafiltration data is (see PF3 sample as an example). Ultrafiltration results are independent of the modelling predictions. Therefore, the strong convergence between ultrafiltration results and Model VI predictions is considered highly significant, providing evidence that this model can accurately predict REE complexation by organic matter in natural waters.

\section{DISCUSSION}

The $\log \mathrm{K}_{\mathrm{MA}}$ and $\log \mathrm{K}_{\mathrm{Mb}}$ values adopted here appear to be the most reliable values derived so far using the LFER method. By confronting Model VI and SHM predictions with published results (Viers et al., 1997) and new ultrafiltration data, we can define the range of conditions under which these models will accurately predict the complexation of REE by organic matter in natural waters. To a first approximation, modelling of World Average River Water (Tang and Johannesson, 2003) suggests that Humic Ion Binding Model and SHM could be equally valuable in modelling REE speciation in low-DOC river waters at circumneutral-pH. However, careful inspection of model results reveals that SHM predicts slightly lower organic complexation for the

HREE than Models V and VI. Some disparities also occur for alkaline waters, with SHM 
predicting an out-competition of the organic complexes over the carbonate complexes, which is not predicted by Model VI. However, these disparities do not really cast doubt on the ability of SHM and Models V and VI to provide a reliable description of REE speciation in rivers, considering that most rivers worldwide are characterized by circumneutral-pH values (Brownlow, 1996). By confronting the model results with ultrafiltration studies, we obtain a somewhat different picture, suggesting that Model VI could be more accurate than SHM in DOC-rich acidic ground- and river waters at circumneutral $\mathrm{pH}$. This apparent poorer ability of SHM to accurately predict REE complexation with organic matter might be due to the different thermodynamic description of HM deprotonation by this model or competition effects between the REE and major dissolved cations such as Fe, Al or Ca. However, as shown below, the difference is more likely due to a higher sensitivity of SHM to the value of the "active DOM parameter", which is required as input into metal-HM complexation models. In fact, careful evaluation of the effects of this parameter on some of the above results shows that, in most cases, SHM could be as accurate as Models V and VI for predicting REE speciation. However, we first need to evaluate the possible effects of differences in HM proton dissociation and major cation competition.

\subsection{Effect of HM proton dissociation}

The main difference between SHM and Model VI is the electrostatic term. Model VI assumes that HM can be represented as rigid spheres of homogeneous size, carrying metal-humic binding sites on their surface with different binding strengths leading to of bidentate and tridentate binding configurations. In this model, electrostatic effects are corrected using equations based on the Debye-Hückel and Gouy-Chapman theories, assuming a homogeneous electrical double layer at the surface of each sphere (Tipping, 1998). In SHM, a discrete-site approach is employed involving eight sites of different acid strength. The bulk of the HM is considered to 
form gels, which are primarily treated as impermeable spheres. The electrostatic interactions on their surfaces are modelled using equations based on the Basic Stern Model (see Gustafsson (2001a) for further details).

Due to these differences in the thermodynamic description of electrostatic effects, the two models assume a different extent of proton dissociation of $\mathrm{HM}$ reactive sites at a given $\mathrm{pH}$. As shown in Fig. 6, Model VI assumes more electronegative HA and FA surfaces at a given pH than SHM, so the density of surface sites available for REE complexation is proportionally higher in Model VI than in SHM. This may partly account for the observed differences in model predictions: (i) indeed, modelling of World Average River Water results shows there is a shift of about $0.75 \mathrm{pH}$ unit between the maximum of LnHM predicted by Model VI and SHM, which is consistent with the difference in electrostatic correction (Figs. 3 and 4); (ii) the proportions of REE complexed with organic matter in Mengong $(\mathrm{pH}=4.6)$ sample are predicted to be slightly higher with Model VI than SHM, which is also consistent; (iii) calculations of REE speciation in three of the four organic-rich circumneutral-pH waters (i.e., PF1, F7 and F14) show differences between Model VI and SHM, with predicted values being at a maximum under acidic $\mathrm{pH}$ (i.e., $\mathrm{F} 7 \mathrm{pH}=6.19)$, which is also as expected from the difference in electrostatic correction.

\subsection{Effect of major competing cations (Fe, Al and Ca)}

Fe, Al and Ca are known to complex strongly with HM (Dupré et al., 1999; Tipping et al., 2002), and can thus compete with REE in metal-HM complexing. As previously shown by Tang and Johannesson (2003), the presence of dissolved Fe and Al can decrease the amount of REE complexed with $\mathrm{HM}$ by $\sim 10 \%$. In the modelling calculations presented here, $\mathrm{Fe}, \mathrm{Al}$ and $\mathrm{Ca}$ are present in solution, and the cation competitive effect is thus taken into account. The two models discussed here can be compared in terms of the relative importance of this effect by considering Table 7, which reports the proportions of $\mathrm{Fe}, \mathrm{Al}$, and $\mathrm{Ca}$ humic complexes predicted by Model 
VI and SHM, as a function of $\mathrm{pH}$. It can be seen that both SHM and Model VI predict roughly the same effect of $\mathrm{Ca}$, which is by far the most abundant cation competing with REE in the three water samples considered here. However, the situation appears different for Fe and Al. We should note two important points: (i) the proportion of Al-HM complexes predicted to occur in circumneutral-pH waters is much higher with SHM than with Model VI; (ii) SHM predicts a much higher competition of the REE with Fe for acidic waters than Model VI. To quantify the effects of the stronger Fe and Al competition imposed by SHM on REE complexation with HM, we re-investigated the four newly ultrafiltered circumneutral-pH water samples (i.e., PF1, PF3, F7 and F14) with this model, assuming no $\mathrm{Al}$ and $\mathrm{Fe}$ in solution. The results indicate that almost all of the REE are bound to $\mathrm{HM}(\sim 100 \%)$. On the other hand, when $\mathrm{Fe}$ and $\mathrm{Al}$ are included in the model, the LnHM species are predicted to account for 47 to $100 \%$ of each REE (depending on the sample; see Table 6). Consequently, SHM appears more sensitive to cation competition than Model VI. The reason for this difference is not clear, as the constants for $\mathrm{Al}, \mathrm{Fe}$ and $\mathrm{Ca}$ used into the two models are derived from the same database (Tipping, 1998; Gustafsson and van Schaik, 2003).

\subsection{Effect of the "active DOM parameter" value}

Apart from the deprotonation and cation competition effects described above, and despite the effects on the uncertainty of $\log \mathrm{K}_{\mathrm{MA}}$ and $\log \mathrm{K}_{\mathrm{Mb}}$ values (see Tang and Johannesson, 2003 for a detailed discussion of the effect of constant uncertainty on Model V), differences in model predictions could result from the use of different values for the "active DOM parameter". In the speciation calculations presented below for World Average River Water and the Mengong and Mar2 samples, we considered as Tang and Johannesson (2003) that the amount of active DOM in these samples is equal to the DOC content. Given that the DOM content of a water sample is approximately twice as high as its DOC concentration, this implies that only $50 \%$ of the DOM 
present in these samples can complex with the REE. In view of the ultrafiltration data reported by Viers et al. (1997), this hypothesis might not be valid for the Mengong and Mar2 samples. Indeed, as shown in Table 3 of Viers et al. (1997), the REE concentrations extrapolated to a zero DOC concentration are positive, rather than negative as in the case of the newly ultrafiltered samples presented in our study. As shown above, calculated active DOM proportions range from 32 to $60 \%$ for the newly ultrafiltred samples, with a mean value of $50 \%$ fully in agreement with Tang and Johannesson's assumption (2003). Evidently, the situation is quite different for the Mengong and Mar2 samples, where ultrafiltration data suggest that $100 \%$ of the DOM present in these samples could be active in complexing the REE.

To test the role of this parameter on model results, we performed sensitivity analysis on the Mengong and Mar2 samples. Model predictions using an "active DOM parameter" set equal to $50 \%$, as suggested by Tang and Johannesson (2003), were compared with results predicted using an "active DOM parameter" of $100 \%$, as indicated by ultrafiltration studies of these samples. We performed the same sensitivity analysis on World Average River Water. However, the newly ultrafiltered samples were not treated, given that ultrafiltration studies of these samples clearly imply that their "active DOM parameter" must be equal to about 50\%. Table 8 shows the results for Mengong and Mar2 samples. Overall, Table 8 shows that raising the "active DOM parameter" from 50 to $100 \%$ strongly increases the proportion of REE that are predicted to be complexed with HM in these two samples. The predicted increase occurs in both Model VI and SHM. Moreover, SHM predictions become similar to Model VI results for Mar2 sample (i.e., LnHM > 98\%) and to ultrafiltration data. However, SHM predictions are still lower than ultrafiltration results for the more acidic Mengong sample. Fig. 7 presents the results of the sensitivity analysis on World Average River Water for La, Eu and Lu. We note a strong difference compared with the predictions obtained for this sample when using an "active DOM parameter" of 50\%. More specifically, both SHM and Model VI indicate that ca. 100\% of the REE should occur as humate complexes at a $\mathrm{pH}$ higher than 6.5. The only remaining noticeable difference is that SHM 
continues to predict a slight deficit in LnHM species at low $\mathrm{pH}$ as compared to Model VI. This effect is known to be due to the lower extent of deprotonation of HM surfaces implied in SHM (see above).

Thus, raising the "active DOM parameter" from 50 to $100 \%$ leads to modifications in the modelling results that are far more important than those generated by differences in the electrostatic terms of the models or by uncertainties in the constant values for REE (see discussion in Tang and Johannesson, 2003) and/or competing cations. When the "active DOM parameter" is set to $100 \%$, it is clearly not unexpected to observe a general increase in the proportion of the REE complexing with HM, as predicted both by Model VI and SHM. This increase in the "active DOM parameter" value is equivalent to enhancing the abundance of organic ligands in sample solutions, which can then quantitatively scavenge all the dissolved REE. The other important key point is that the change in "active DOM parameter" value leads to a strong reduction of the disparities produced in model predictions for World Average River Water, and the Mengong and Mar2 samples (compare Figs. 3 and 7, and Tables 5 and 8). Thus, by adopting an "active DOM parameter" of $100 \%$, we obtain a fit between SHM and the ultrafiltration data for Mengong and Mar2 samples that is much better than previously established using a value of $50 \%$ for this parameter in SHM (see Tables 5 and 8).

Finally, two key questions arise from this study: what value should be adopted for the proportion of active DOM occurring in natural solutions (50 or 100\%), and is this proportion constant from one natural solution to another? Considering the present ultrafiltration results and those obtained by Viers et al. (1997), it appears that the proportion of active DOM does not remain constant in waters, varying from 32 to $59 \%$ in the newly ultrafiltered samples, to $100 \%$ in the Mengong and Mar2 samples. A literature survey indicates that, in any case, this ratio could be significantly higher than the value of $50 \%$ used by Tang and Johannesson in their 2003 study. For example, a detailed study by Bryan et al. (2002) of the proportion of DOM that can complex metals (e.g., $\mathrm{Cu}$ and $\mathrm{Al}$ ) in natural waters showed this amount to be $\approx 65 \%$ in most cases. This 
proportion is clearly lower than the value of $100 \%$ set in our sensitivity analysis, but significantly higher than the value of 50\% used by Tang and Johannesson (2003).

To conclude, the above sensitivity analysis indicates that it is critical to have prior knowledge of the amount of active DOM in a water before making use of SHM or Model VI to predict the speciation of REE in waters. This implies that ultrafiltration experiments and/or other analytical techniques able to determine the REE complexing capacity of DOM must be performed on the samples that we wish to model.

\section{CONCLUSION}

The scope of this study was to increase our understanding of how to describe REE-organic complexation in equilibrium speciation models. For this purpose, we compared the ability of SHM and Models V and VI to assess the role of DOM in the speciation of REE in organic-rich ground- and river waters. We used REE specific equilibrium constants estimated by LFER, applying complexation constants for REE with acetic acid. The advantage of testing SHM is that this model is part of a wider equilibrium model (Visual MINTEQ) that also allows modelling of dissolution/precipitation, sorption/desorption and oxidation/reduction. Both Model VI and SHM yield comparable results for World Average River Water, confirming the earlier finding that a large fraction of the dissolved REE in rivers occurs as organic complexes. This also suggests that the two models could be equally valuable for calculating REE speciation in low-DOC waters at circumneutral-pH. The two models also successfully reproduce ultrafiltration results obtained for acidic, DOC-rich ground- and river waters. However, the two models are found to yield slightly different results (depending on sample) when compared to newly obtained ultrafiltration results

for organic-rich (DOC>7 mg L $\mathrm{m}^{-1}$ ) groundwaters at circumneutral $\mathrm{pH}$, where Model VI predictions are in closer agreement with the ultrafiltration data than SHM. A survey of ultrafiltration results allows us to determine the "active DOM parameter" for the newly ultrafiltered water data. Thus, 
the observed discrepancy between SHM predictions and ultrafiltration results cannot be due to the input of inappropriate "active DOM parameter" values in this model. Clearly, SHM appears to need some improvements to become a REE speciation model of universal application (i.e., also usable under acidic $\mathrm{pH}$ conditions). Moreover, sensitivity analysis indicates that the "active DOM parameter" is a key parameter for both Model VI and SHM. Consideration of previously published speciation results based on Model V shows that great care should be taken in making use of these results because of the possible introduction of inappropriate values for this parameter. The results presented in this study show that, before running speciation models, it is essential to know the proportion of DOM that is active in complexing REE in a given water sample. This requirement could severely complicate the use of models to assess the role of DOM in controlling the speciation of REE in natural waters. 
Acknowledgements. We thank the technical staff at Rennes (M. Le Coz-Bouhnik, O. Hénin and P. Petitjean) for their assistance during the experimental and analytical work. Dr. M.S.N. Carpenter is acknowledged for English corrections. J.E. Sonke, K.H. Johannesson and several anonymous reviewers are thanked for thorough and constructive comments of an earlier version of this paper. This research was supported by the CPER programmes "Développement de la Recherche sur la Maîtrise de la Qualité de l'Eau en Bretagne" jointly funded by the French Government and the Council of Rennes Métropole. 


\section{APPENDIX 1 - Ultrafiltration procedure and chemical analyses}

Samples were collected in November 2004 from shallow piezometers ( 0.5 to $1.5 \mathrm{~m}$ deep). The $\mathrm{pH}$ was measured in the field with a combined Sentix 50 electrode. The accuracy of $\mathrm{pH}$ measurements is estimated at $\pm 0.05 \mathrm{pH}$ unit. About $60 \mathrm{~mL}$ of each sample were immediately filtered on site, through $0.2 \mu \mathrm{m}$ cellulose acetate filter (Sartorius Minisart). An aliquot of $30 \mathrm{~mL}$ was acidified on site and subsequently used to measure major and trace cation concentrations. The remaining $30 \mathrm{~mL}$ were not acidified and used to measure alkalinity, major anions and DOC concentrations. For each sample, an extra $1 \mathrm{~L}$ aliquot was collected. This extra aliquot was filtered in the laboratory through $0.2 \mu \mathrm{m}$ cellulose acetate membrane using a Sartorius Teflon filtration unit. Thirty $\mathrm{mL}$ of the filtrate were acidified and used to re-measure major and trace cation concentrations (including REE), while $10 \mathrm{~mL}$ were used to re-measure the major anions and DOC content. Ultrafiltration experiments were performed with the remaining filtrate. Ultrafiltrations were carried out with $15 \mathrm{~mL}$ centrifugal tubes equipped with permeable membranes of decreasing pore-size cut off (Millipore Amicon Ultra-15): $30 \mathrm{kDa}, 10 \mathrm{kDa}$ and 5 $\mathrm{kDa}$. Each centrifugal filter device was washed and rinsed with $\mathrm{HCl} 0.1 \mathrm{~N}$ and MilliQ water two times before use. Centrifugations were performed using a Jouan G4.12 centrifuge equipped with swinging bucket, at $3000 \mathrm{~g}$ for between $20(30 \mathrm{kDa}$ and $10 \mathrm{kDa})$ and $30(5 \mathrm{kDa})$ minutes, depending on the pore-size cut off. Each of the four investigated samples (PF1, PF3, F7 and F14) was ultrafiltered in duplicate. All experiments were performed at room temperature: $20 \pm 2{ }^{\circ} \mathrm{C}$. Further information on the centrifugation procedure can be found in Pourret et al. (2007b).

Alkalinity was determined by potentiometric titration with an automatic titrator (794 Basic Titrino Methrom). Major anion $\left(\mathrm{Cl}^{-}, \mathrm{SO}_{4}{ }^{2-}\right.$ and $\left.\mathrm{NO}_{3}{ }^{-}\right)$concentrations were measured by ionic chromatography (Dionex DX-120). Major cation and trace element concentrations were determined by ICPMS (Agilent 4500), using indium as an internal standard. Dissolved organic carbon (DOC) was analysed on a total organic carbon analyzer (Shimadzu TOC-5050A). Typical 
uncertainties on anion and cation measurements, as established from repeated analyses of standard solutions (SLRS 4 geostandard water solution for cations; K-biphtalate solutions for DOC; Dionex seven anions standard solutions for anions), are estimated at $< \pm 4 \%$ for anions and at $< \pm 5 \%$ for all other measured species.

All procedures (sampling, filtration, storing and analysis) were carried out in order to minimize contamination. Samples were stored in acid-washed Nalgene polypropylene containers

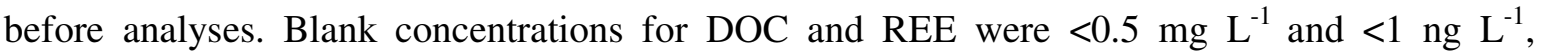
respectively. All reported DOC concentrations are blank corrected (maximum correction $=8 \%$ ). For the REE, there was no need for blank corrections, since the sample concentrations were systematically two to three orders of magnitude higher than blank levels. The instrumental error on REE analysis in our laboratory as established from repeated analyses of multi-REE standard solution (Accu Trace ${ }^{\mathrm{TM}}$ Reference, USA) and of the SLRS-4 water standard is $< \pm 2 \%$ (Dia et al., 2000; Davranche et al., 2004; Gruau et al., 2004; Davranche et al., 2005). 


\section{TABLE AND FIGURE CAPTIONS}

Table 1. Log $\mathrm{K}$ for metal complexation with lactic acid (LA), acetic acid (AA) and first hydrolysis $(\mathrm{OH})$, as well as $\log \mathrm{K}_{\mathrm{MA}}$ for HA and FA (from Tipping, 1998), used to obtain equations for LFER between $\log \mathrm{K}_{\mathrm{MA}}$ and $\log \mathrm{K}$ for each ligand. Log $\mathrm{K}$ for AA, LA and $\mathrm{OH}$ are from NIST Database (Martell and Smith, 1998) for $25^{\circ} \mathrm{C}$ and zero ionic strength conditions.

Table 2. $\log \mathrm{K}_{2}$ for metal complexation with lactic acid (LA), acetic acid (AA) and hydrolysis $(\mathrm{OH})$, as well as $\log \mathrm{K}_{\mathrm{Mb}}$ for HA and FA (from Gustafsson and van Schaik, 2003), used to obtain equations for LFER between $\log \mathrm{K}_{\mathrm{Mb}}$ and $\log \mathrm{K}_{2}$ for each ligand. Log $\mathrm{K}$ values for LA, AA and $\mathrm{OH}$ are taken from NIST Database (Martell and Smith, 1998) at $25^{\circ} \mathrm{C}$ and zero ionic strength conditions.

Table 3. Summary of estimated log $\mathrm{K}_{\mathrm{MA}}$ for the REE.

Table 4. Summary of estimated $\log \mathrm{K}_{\mathrm{Mb}}$ for the REE.

Table 5. Proportions of LnHM complexes calculated with Model V (Tang and Johannesson, 2003), Model VI and SHM for Mengong and Mar2 water samples. Fraction of LnHM complexes previously estimated for these two samples by ultrafiltration experiments are shown for comparison (Viers et al., 1997). The proportion of DOM active in complexing the REE is assumed to be $50 \%$ (i.e., active DOM content $=$ DOC content).

Table 6. Comparison between the proportions of LnFA and LnHA complexes in PF1, PF3, F7 and F14 samples obtained by ultrafiltration experiments and modelling calculation using 
Model VI and SHM. Proportions of DOM active in complexing the REE were calculated from ultrafiltration results (see text for further explanation).

Table 7. Model VI and SHM speciation calculations for Fe, Al and $\mathrm{Ca}$ in World Average River Water as a function of $\mathrm{pH}$.

Table 8. Model VI and SHM predictions of the proportion of REE occurring as humate complexes in Mengong and Mar2 waters, with the "active DOM parameter" assumed to be equal to $100 \%$. Ultrafiltration data shown for comparison are from Viers et al. (1997).

Table EA1. Values adopted in this study for Model VI parameters (based on Tipping, 1998).

Table EA2. Values adopted in this study for SHM parameters (based on Gustafsson, 2001b).

Table EA3. Concentrations of major solutes (in $\mu \mathrm{mol} \mathrm{L} \mathrm{L}^{-1}$ ), alkalinity (in $\mu \mathrm{mol} \mathrm{L} \mathrm{L}^{-1}$ ), REE (in nmol $\mathrm{L}^{-1}$ ), and DOC (in $\mathrm{mg} \mathrm{L}^{-1}$ ) in ultrafiltered groundwaters.

Table EA4. Concentrations of trace metal (in $\mu \mathrm{mol} \mathrm{L}^{-1}$ ), REE (in $\mathrm{nmol} \mathrm{L} \mathrm{L}^{-1}$ ) and DOC (in $\mathrm{mg} \mathrm{L}^{-}$ ${ }^{1}$ ) in the ultrafiltrates.

Fig. 1. Linear free-energy relationships between $\log K_{M A}$ and $\log K(L A), \log K(A A)$ and $\log$ $\mathrm{K}(\mathrm{OH})$ listed in Table 2. $\log \mathrm{K}(\mathrm{LA}), \log \mathrm{K}(\mathrm{AA})$ and $\log \mathrm{K}(\mathrm{OH})$ are from the NIST Database (Martell and Smith, 1998), whereas log $\mathrm{K}_{\mathrm{MA}}$ values are from Tipping (1998). Standard deviations are indicated where available. Dashed lines indicate $95 \%$ confidence intervals of linear fits. Shaded areas mark fields of available K(LA), log K(AA) and $\log$ $\mathrm{K}(\mathrm{OH})$ data. 
Fig. 2. Linear free-energy relationships between $\log \mathrm{K}_{\mathrm{Mb}}$ and $\log \mathrm{K}_{2}(\mathrm{LA}), \log \mathrm{K}_{2}(\mathrm{AA})$ and $\log$ $\mathrm{K}_{2}(\mathrm{OH})$ listed in Table 5. The AA, LA and $\mathrm{OH}$ constants values are from the NIST Database (Martell and Smith, 1998), and the values of log $\mathrm{K}_{\mathrm{Mb}}$ are from the "shmgeneric" Database (Gustafsson, 2001b). Dashed lines indicate 95\% confidence intervals of linear fits. Shaded areas mark fields of available $\log K_{2}(\mathrm{LA}), \log \mathrm{K}_{2}(\mathrm{AA})$ and $\log \mathrm{K}_{2}(\mathrm{OH})$ data.

Fig. 3. Model VI speciation calculations for (a) La, (b) Eu and (c) Lu in World Average River Water as a function of $\mathrm{pH}$. The proportion of active DOM complexing the REE is assumed to be $50 \%$ (i.e., active DOM content $=$ DOC content).

Fig. 4. SHM speciation calculations for (a) La, (b) Eu and (c) Lu in World Average River Water as a function of $\mathrm{pH}$. The proportion of active DOM complexing the REE is assumed to be $50 \%$ (i.e., active DOM content = DOC content).

Fig. 5. $\Sigma$ REE and Fe concentrations as a function of DOC concentrations in the successive filtrates $(<0.2 \mu \mathrm{m},<30 \mathrm{kDa},<10 \mathrm{kDa},<5 \mathrm{kDa})$ for (a) PF3, (b) F7, (c) F14 and (d) PF1 water samples. Error bars correspond to standard deviations for two replicates, with some error bars being smaller than the symbol size. Point A represents the extrapolated amount of REE thought to be bound to humic matter, whereas point B gives the DOC content extrapolated to a REE content equal to 0 (see text for further explanation).

Fig. 6. Comparison of extent of proton dissociation for HA and FA calculated by Model VI and SHM as a function of $\mathrm{pH}$. 
Fig. 7. Model VI and SHM speciation calculations for (a) La, (b) Eu and (c) $\mathrm{Lu}$ for World Average River Water illustrating the effects of setting a value of $100 \%$ for the "active DOM parameter" on the proportion of REE complexed with HM in this sample, as a function of $\mathrm{pH}$ (see Figs. 3 and 4, for comparison). 


\section{REFERENCES}

Aubert D., Stille P., and Probst A. (2001) REE fractionation during granite weathering and removal by waters and suspended loads: $\mathrm{Sr}$ and $\mathrm{Nd}$ isotopic evidence. Geochim. Cosmochim. Acta 65, 387-406.

Bau M. (1999) Scavenging of dissolved yttrium and rare earths by precipitating iron oxyhydroxide: Experimental evidence for Ce oxidation, Y-Ho fractionation, and lanthanide tetrad effect. Geochim. Cosmochim. Acta 63, 67-77.

Bidoglio G., Grenthe I., Qi P., Robouch P., and Omenetto N. (1991) Complexation of Eu and Tb with fulvic acids as studied by time-resolved laser induced fluorescence. Talanta 38, 9991008.

Brownlow A. H. (1996) Geochemistry. Prentice Hall, Englewood Cliffs, NJ.

Bryan S. E., Tipping E., and Hamilton-Taylor J. (2002) Comparison of measured and modelled copper binding by natural organic matter in freshwaters. Comp. Biochem. Physiol. C 133, $37-49$.

Byrne R. H. and Sholkovitz E. R. (1996) Marine chemistry and geochemistry of the lanthanides. In Handbook on the Physics and Chemistry of Rare Earths (eds. K.A. Gschneidner, Jr. and L.R. Eyring), Vol. 23, pp. 497-593. Elsevier Sciences B.V.

Coppin, F., Berger, G., Bauer, A., Castet, S. and Loubet, M., 2002. Sorption of lanthanides on smectite and kaolinite. Chemical Geology, 182: 57-68.

Davranche M., Pourret O., Gruau G., and Dia A. (2004) Impact of humate complexation on the adsorption of REE onto Fe oxyhydroxide. J. Colloid Interface Sci. 277, 271-279.

Davranche M., Pourret O., Gruau G., Dia A., and Le Coz-Bouhnik M. (2005) Adsorption of REE(III)-humate complexes onto $\mathrm{MnO}_{2}$ : Experimental evidence for cerium anomaly and lanthanide tetrad effect suppression. Geochim. Cosmochim. Acta, 69, 4825-4835. 
De Baar H. J. W., German C. R., Elderfield H., and van Gaans P. (1988) Rare earth element distributions in anoxic waters of the Cariaco Trench. Geochim. Cosmochim. Acta 52, 1203-1219.

De Baar H. J. W., Schijf J., and Byrne R. H. (1991) Solution chemistry of the rare earth elements in seawater. Eur. J. Solid State Inorganic Chem. 28, 357-373.

Deberdt S., Castet S., Dandurand J.-L., Harrichoury J.-C., and Louiset I. (1998) Experimental study of $\mathrm{La}(\mathrm{OH})_{3}$ and $\mathrm{Gd}(\mathrm{OH})_{3}$ solubilities $\left(25\right.$ to $\left.150^{\circ} \mathrm{C}\right)$, and La-acetate complexing (25 to $\left.80^{\circ} \mathrm{C}\right)$. Chem. Geol. 151, 349-372.

Dia A., Gruau G., Olivié-Lauquet G., Riou C., Molénat J., and Curmi P. (2000) The distribution of rare earth elements in groundwaters: assessing the role of source-rock composition, redox changes and colloidal particle. Geochim. Cosmochim. Acta 64, 4131-4151.

Dupré B., Viers J., Dandurand J.-L., Polvé M., Bénézeth P., Vervier P., and Braun J.-J. (1999) Major and trace elements associated with colloids in organic-rich river waters: ultrafiltration of natural and spiked solutions. Chem. Geol. 160, 63-80.

Elderfield H. and Greaves M. J. (1982) The rare earth elements in seawater. Nature 296, 214219.

Elderfield H., Upstill-Goddard R., and Sholkovitz E. R. (1990) The rare earth elements in rivers, estuaries, and coastal seas and their significance to the composition of ocean waters. Geochim. Cosmochim. Acta 54, 971-991.

Gosselin D. C., Smith M. R., Lepel E. A., and Laul J. C. (1992) Rare earth elements in chloriderich groundwater, Palo Duro Basin, Texas, USA. Geochim. Cosmochim. Acta 56, 14951505.

Gruau G., Dia A., Olivié-Lauquet G., Davranche M., and Pinay G. (2004) Controls on the distribution of rare earth elements in shallow groundwaters. Wat. Res. 38, 3576-3586.

Gustafsson J. P. (2001a) Modeling the acid-base properties and metal complexation of humic substances with the Stockholm Humic Model. J. Colloid Interface Sci. 244, 102-112. 
Gustafsson J. P. (2001b) http://www.lwr.kth.se/english/OurSoftware/vminteq/index.htm.

Gustafsson J. P., Pechova P., and Berggren D. (2003) Modeling metal binding to soils: the role of natural organic matter. Environ. Sci. Technol. 37, 2767-2774.

Gustafsson J. P. and van Schaik J. W. J. (2003) Cation binding in a mor layer: batch experiments and modelling. European Journal of Soil Science 54, 295-310.

Ingri J., Widerlund A., Land M., Gustafsson O., Andersson P., and Ohlander B. (2000) Temporal variations in the fractionation of the rare earth elements in a boreal river; the role of colloidal particles. Chem. Geol. 166, 23-45.

Janssen R. P. T. and Verweij W. (2003) Geochemistry of some rare earth elements in groundwater, Vierlingsbeek, The Netherlands. Wat. Res. 37, 1320-1350.

Johannesson K. H., Farnham I. M., Guo C., and Stetzenbach K. J. (1999) Rare earth element fractionation and concentration variations along a groundwater flow path within a shallow, basin-fill aquifer, southern Nevada, USA. Geochim. Cosmochim. Acta 63, 26972708.

Johannesson K. H. and Hendry M. J. (2000) Rare earth element geochemistry of groundwaters from a thick till and clay-rich aquitard sequence, Saskatchewan, Canada. Geochim. Cosmochim. Acta 64, 1493-1509.

Johannesson K. H., Stetzenbach K. J., and Hodge V. F. (1997) Rare earth elements as geochemical tracers of regional groundwater mixing. Geochim. Cosmochim. Acta 61, $3605-3618$.

Johannesson K. H., Zhou X., Guo C., Stetzenbach K. J., and Hodge V. F. (2000) Origin of rare earth element signatures in groundwaters of circumneutral $\mathrm{pH}$ from southern Nevada and eastern California, USA. Chem. Geol. 164, 239-257.

Johannesson K. H., Tang J., Daniels J. M., Bounds W. J., and Burdige D. J. (2004) Rare earth element concentrations and speciation in organic-rich blackwaters of the Great Dismal Swamp, Virginia, USA. Chem. Geol. 209, 271-294. 
Klungness G. D. and Byrne R. H. (2000) Comparative hydrolysis behavior of the rare earths and yttrium: the influence of temperature and ionic strength. Polyhedron 19, 99-107.

Lead J. R., Hamilton-Taylor J., Peters A., Reiner S., and Tipping E. (1998) Europium binding by fulvic acids. Anal. Chim. Acta 369, 171-180.

Lippold H., Müller N., and Kupsch H. (2005) Effect of humic acid on the pH-dependent adsorption of terbium(III) onto geological materials. Appl. Geochem. 20, 1209-1217.

Luo Y.-R. and Byrne R. H. (2004) Carbonate complexation of Yttrium and the rare earth elements in natural rivers. Geochim. Cosmochim. Acta 68, 691-699.

Maes A., De Brabandere J., and Cremers A. (1988) A modified Schubert method for the measurement of the stability of europium humic acid complexes in alkaline conditions. Radiochim. Acta 44/45, 51-57.

Martell A. E. and Smith R. M. (1998) NIST Critical Selected Stability Constants of Metal Complexes Database, available at: http://www.nist.gov/srd/nist46.htm.

Milne C. J., Kinniburgh D. G., and Tipping E. (2001) Generic NICA-Donnan Model parameters for proton binding by humic substances. Environ. Sci. Technol. 35, 2049-2059.

Milne C. J., Kinniburgh D. G., Van Riemsdijk W. H., and Tipping E. (2003) Generic NICADonnan model parameters for Metal-Ion binding by humic substances. Environ. Sci. Technol. 37, 958-971.

Moulin V., Tits J., Moulin C., Decambox P., Mauchien P., and de Ruty O. (1992) Complexation behaviour of humic substances towards actinides and lanthanides studied by TimeResolved Laser-Induced Spectrofluometry. Radiochim. Acta 58/59, 121-128.

Nelson B. J., Wood S. A., and Osiensky J. L. (2004) Rare earth element geochemistry of groundwater in the Palouse Basin, northern Idaho-eastern Washington. Geochemistry: Exploration, Environment, Analysis 4, 227-241.

Olivié-Lauquet G., Gruau G., Dia A., Riou C., Jaffrezic A., and Henin O. (2001) Release of trace elements in wetlands: role of seasonal variability. Wat. Res. 35, 943-952. 
Pourret O., Davranche M., Gruau G., and Dia A. (2007a) Competition between humic acid and carbonates for rare earth elements complexation. J. Colloid Interface Sci. 305, 25-31.

Pourret O., Dia A., Davranche M., Gruau G., Hénin O., and Angée M. (2007b) Organo-colloidal control on major- and trace-element partitioning in shallow groundwaters: confronting ultrafiltration and modelling. Appl. Geochem. doi: 10.1016:j.apgeochem.2007.02.007

Ramsey J. B. (1969) Tests for specification errors in classical linear least-squares regression analysis. Journal of the Royal Statistical Society, Series B XXXI ( Part 2), 350.

Schijf J. and Byrne R. H. (2004) Determination of $\mathrm{SO}_{4} \beta_{1}$ for yttrium and the rare earth elements at $\mathrm{I}=0.66 \mathrm{~m}$ and $\mathrm{t}=25^{\circ} \mathrm{C}$-Implications for YREE solution speciation in sulfate-rich waters. Geochim. Cosmochim. Acta 68, 2825-2837.

Sholkovitz E. R. (1995) The aquatic chemistry of rare earth elements in rivers and estuaries. Aquat. Geochem. 1, 1-34.

Smedley P. L. (1991) The geochemistry of rare earth elements in groundwater from the Carnmenellis area, southwest England. Geochim. Cosmochim. Acta 55, 2767-2779.

Sonke J. E. and Salters V. J. M. (2006) Lanthanide-humic substances complexation. I. Experimental evidence for a lanthanide contraction effect. Geochim. Cosmochim. Acta 70, 1495-1506.

Tang J. and Johannesson K. H. (2003) Speciation of rare earth elements in natural terrestrial waters: Assessing the role of dissolved organic matter from the modeling approach. Geochim. Cosmochim. Acta 67, 2321-2339.

Tanikazi Y., Shimokawa T., and Nakamura M. (1992) Physicochemical speciation of trace elements in river waters by size fractionation. Environ. Sci. Technol. 26, 1433-1444.

Tipping E. (1994) WHAM - A chemical equilibrium model and computer code for waters, sediments, and soils incorporating a discrete site/electrostatic model of ion-binding by humic substances. Comput. Geosci. 20, 973-1023. 
Tipping E. (1998) Humic Ion-Binding Model VI: an improved description of the interactions of protons and metal ions with humic substances. Aquat. Geochem. 4, 3-48.

Tipping E. and Hurley M. A. (1992) A unifying model of cation binding by humic substances. Geochim. Cosmochim. Acta 56, 3627-3641.

Tipping E., Rey-Castro C., Bryan S. E., and Hamilton-Taylor J. (2002) Al(III) and Fe(III) binding by humic substances in freshwaters, and implication for trace metal speciation. Geochim. Cosmochim. Acta 66, 3211-3224.

Viers J., Dupré B., Polvé M., Schott J., Dandurand J.-L., and Braun J. J. (1997) Chemical weathering in the drainage basin of a tropical watershed (Nsimi-Zoetele site, Cameroon): comparison between organic-poor and organic-rich waters. Chem. Geol. 140, 181-206.

Wood S. A. (1993) The aqueous geochemistry of the rare-earth elements: Critical stability constants for complexes with simple carboxylic acids at $25^{\circ} \mathrm{C}$ and 1 bar and their application to nuclear waste management. Eng. Geol. 34, 229-259.

Yamamoto Y., Takahashi Y., and Shimizu H. (2005) Systematics of stability constants of fulvate complexes with rare earth ions. Chemistry Letters 34, 880-881.

Yamamoto Y., Takahashi Y., and Shimizu H. (2006) Interpretation of REE patterns in natural water based on the stability constants. Geochim. Cosmochim. Acta Goldschmidt Conference Abstracts, doi:10.1016/j.gca.2006.06.1587. 


\begin{tabular}{ccccccc}
\hline Metals & $\log \mathrm{K}(\mathrm{LA})$ & $\log \mathrm{K}(\mathrm{AA})$ & $\log \mathrm{K}(\mathrm{MOH})$ & $\log \mathrm{K}_{\mathrm{MA}}(\mathrm{HA})$ & $\log \mathrm{K}_{\mathrm{MA}}(\mathrm{FA})$ & $\Delta \mathrm{LK}_{2}$ \\
\hline $\mathrm{Mg}^{2+}$ & 1.37 & 1.27 & 2.60 & 0.70 & 1.10 & 0.12 \\
$\mathrm{Ca}^{2+}$ & 1.45 & 1.18 & 1.30 & 0.70 & 1.30 & 0.0 \\
$\mathrm{Sr}^{2+}$ & 0.97 & 1.14 & 0.82 & 1.11 & 1.20 & 0.0 \\
$\mathrm{Mn}^{2+}$ & 1.43 & 1.4 & 3.40 & 0.60 & 1.70 & 0.58 \\
$\mathrm{Co}^{2+}$ & 1.90 & 1.46 & 4.35 & 1.10 & 1.40 & 1.22 \\
$\mathrm{Ni}^{2+}$ & 2.22 & 1.43 & 4.14 & 1.10 & 1.40 & 1.57 \\
$\mathrm{Cu}^{2+}$ & 3.02 & 2.22 & 6.50 & 2.00 & 2.10 & 2.34 \\
$\mathrm{Zn}^{2+}$ & 2.22 & 1.57 & 5.00 & 1.50 & 1.60 & 1.28 \\
$\mathrm{Cd}^{2+}$ & 1.70 & 1.93 & 3.09 & 1.30 & 1.60 & 1.48 \\
$\mathrm{~Pb}^{2+}$ & 2.78 & 2.68 & 6.40 & 2.00 & 2.20 & 0.93 \\
$\mathrm{Al}^{3+}$ & 3.30 & 2.57 & 9.00 & 2.60 & 2.50 & 0.46 \\
\hline
\end{tabular}

Table 1 


\begin{tabular}{ccccc}
\hline Metals & $\log \mathrm{K}_{2}(\mathrm{LA})$ & $\log \mathrm{K}_{2}(\mathrm{AA})$ & $\log \mathrm{K}_{2}(\mathrm{OH})$ & $\log \mathrm{K}_{\mathrm{Mb}}$ \\
\hline $\mathrm{Ca}^{2+}$ & 2.45 & - & - & -11.30 \\
$\mathrm{Mn}^{2+}$ & 2.10 & - & 5.8 & - \\
$\mathrm{Cu}^{2+}$ & 4.84 & 3.63 & 11.8 & -5.80 \\
$\mathrm{Zn}^{2+}$ & 3.75 & 1.36 & 10.2 & -9.00 \\
$\mathrm{Cd}^{2+}$ & 2.74 & 2.86 & 7.7 & -9.30 \\
$\mathrm{~Pb}^{2+}$ & 3.61 & 4.08 & 10.9 & -6.15 \\
$\mathrm{Al}^{3+}$ & 5.97 & 4.55 & 17.9 & -4.20 \\
$\mathrm{Co}^{2+}$ & 3.07 & 1.10 & 9.2 & -10.10 \\
\hline
\end{tabular}

Table 2. 


\begin{tabular}{ccccccccc}
\hline & \multicolumn{4}{c}{$\log \mathrm{K}_{\mathrm{MA}}$ (HA) } & \multicolumn{4}{c}{$\log \mathrm{K}_{\mathrm{MA}}$ (FA) } \\
& $\begin{array}{c}\text { From } \\
\text { LA }\end{array}$ & $\begin{array}{c}\text { From } \\
\text { AA }\end{array}$ & $\begin{array}{c}\text { From } \\
\text { OH }\end{array}$ & $\begin{array}{c}\text { Adopted } \\
\text { estimated }\end{array}$ & $\begin{array}{c}\text { From } \\
\text { LA }\end{array}$ & $\begin{array}{c}\text { From } \\
\text { AA }\end{array}$ & $\begin{array}{c}\text { From } \\
\text { OH }\end{array}$ & $\begin{array}{c}\text { Adopted } \\
\text { estimated }\end{array}$ \\
REE & (Eqn. 1) & (Eqn. 3) & (Eqn. 5) & values & (Eqn. 2) & (Eqn. 4) & (Eqn. 6) & values \\
\hline $\mathrm{La}$ & 2.30 & 2.20 & 1.54 & 2.20 & 2.30 & 2.27 & 1.80 & 2.27 \\
$\mathrm{Ce}$ & 2.45 & 2.25 & 1.66 & 2.25 & 2.40 & 2.31 & 1.88 & 2.31 \\
$\mathrm{Pr}$ & 2.46 & 2.30 & 1.66 & 2.30 & 2.40 & 2.35 & 1.88 & 2.35 \\
$\mathrm{Nd}$ & 2.47 & 2.32 & 1.69 & 2.32 & 2.41 & 2.37 & 1.90 & 2.37 \\
$\mathrm{Sm}$ & 2.53 & 2.50 & 1.77 & 2.50 & 2.45 & 2.49 & 1.96 & 2.49 \\
$\mathrm{Eu}$ & 2.56 & 2.42 & 1.79 & 2.42 & 2.47 & 2.44 & 1.97 & 2.44 \\
$\mathrm{Gd}$ & 2.54 & 2.31 & 1.78 & 2.31 & 2.46 & 2.36 & 1.96 & 2.36 \\
$\mathrm{~Tb}$ & 2.56 & 2.20 & 1.82 & 2.20 & 2.47 & 2.27 & 1.99 & 2.27 \\
$\mathrm{Dy}$ & 2.55 & 2.13 & 1.83 & 2.13 & 2.47 & 2.23 & 2.00 & 2.23 \\
$\mathrm{Ho}$ & 2.59 & 2.09 & 1.84 & 2.09 & 2.49 & 2.20 & 2.01 & 2.20 \\
$\mathrm{Er}$ & 2.60 & 2.07 & 1.85 & 2.07 & 2.50 & 2.18 & 2.01 & 2.18 \\
$\mathrm{Tm}$ & 2.62 & 2.11 & 1.88 & 2.11 & 2.51 & 2.21 & 2.04 & 2.21 \\
$\mathrm{Yb}$ & 2.64 & 2.21 & 1.91 & 2.21 & 2.53 & 2.28 & 2.06 & 2.28 \\
$\mathrm{Lu}$ & 2.72 & 2.13 & 1.91 & 2.13 & 2.58 & 2.23 & 2.06 & 2.23 \\
\hline
\end{tabular}

Table 3. 


\begin{tabular}{|c|c|c|c|c|}
\hline \multirow[b]{2}{*}{ REE } & \multicolumn{3}{|c|}{$\log \mathrm{K}_{\mathrm{Mb}}$} & \multirow[b]{2}{*}{$\begin{array}{c}\text { Adopted } \\
\text { estimated } \\
\text { values }\end{array}$} \\
\hline & $\begin{array}{c}\text { From } \\
\text { LA } \\
\text { (Eqn. 7) }\end{array}$ & $\begin{array}{c}\text { From } \\
\text { AA } \\
\text { (Eqn. 8) }\end{array}$ & $\begin{array}{c}\text { From } \\
\text { OH } \\
\text { (Eqn. 9) }\end{array}$ & \\
\hline $\mathrm{La}$ & -5.74 & -5.66 & -7.82 & -5.66 \\
\hline $\mathrm{Ce}$ & -5.02 & -5.60 & -7.65 & -5.60 \\
\hline $\operatorname{Pr}$ & -4.68 & -5.13 & -7.59 & -5.13 \\
\hline $\mathrm{Nd}$ & -4.55 & -5.04 & -7.53 & -5.04 \\
\hline $\mathrm{Sm}$ & -4.32 & -4.65 & -7.36 & -4.65 \\
\hline $\mathrm{Eu}$ & -4.15 & -4.79 & -7.36 & -4.79 \\
\hline $\mathrm{Gd}$ & -4.41 & -5.04 & -7.25 & -5.04 \\
\hline $\mathrm{Tb}$ & -4.11 & -5.40 & -7.19 & -5.40 \\
\hline Dy & -3.83 & -5.50 & -7.13 & -5.50 \\
\hline Ho & -3.70 & -5.57 & -7.08 & -5.57 \\
\hline $\mathrm{Er}$ & -3.32 & -5.65 & -6.96 & -5.65 \\
\hline $\mathrm{Tm}$ & -3.15 & -5.71 & -6.96 & -5.71 \\
\hline $\mathrm{Yb}$ & -2.94 & -5.30 & -6.91 & -5.30 \\
\hline $\mathrm{Lu}$ & -2.83 & -5.50 & -6.85 & -5.50 \\
\hline
\end{tabular}

Table 4. 


\begin{tabular}{c|cccc|cccc}
\hline & \multicolumn{4}{|c}{ Mengong } & \multicolumn{4}{c}{ Mar2 } \\
& Ultrafiltration & Model V & Model VI & SHM & Ultrafiltration & Model V & Model VI & SHM \\
& \% LnHM & \% LnHM & \% LnHM & \% LnHM & \% LnHM & \% LnHM & \% LnHM & \% LnHM \\
\hline La & 86 & 63 & 60 & 39 & 94 & 87 & 99 & 95 \\
$\mathrm{Ce}$ & 86 & 72 & 65 & 40 & 94 & 91 & 99 & 95 \\
$\mathrm{Pr}$ & 87 & 76 & 71 & 55 & 96 & 92 & 100 & 97 \\
$\mathrm{Nd}$ & 86 & 77 & 74 & 59 & 95 & 93 & 100 & 98 \\
$\mathrm{Sm}$ & 100 & 86 & 90 & 71 & 100 & 96 & 100 & 99 \\
$\mathrm{Gd}$ & 100 & 80 & 73 & 52 & 100 & 94 & 100 & 98 \\
$\mathrm{~Tb}$ & 100 & 77 & 60 & 46 & 100 & 93 & 99 & 95 \\
$\mathrm{Dy}$ & 100 & 75 & 52 & 43 & 100 & 92 & 99 & 94 \\
$\mathrm{Ho}$ & 100 & 75 & 48 & 41 & 100 & 92 & 98 & 93 \\
$\mathrm{Er}$ & 69 & 75 & 46 & 39 & 100 & 93 & 98 & 91 \\
$\mathrm{Tm}$ & 100 & 77 & 50 & 38 & 100 & 93 & 98 & 90 \\
$\mathrm{Yb}$ & 100 & 78 & 61 & 41 & 100 & 93 & 99 & 96 \\
$\mathrm{Lu}$ & 100 & 81 & 52 & 34 & 100 & 95 & 99 & 94 \\
\hline
\end{tabular}

Table 5. 


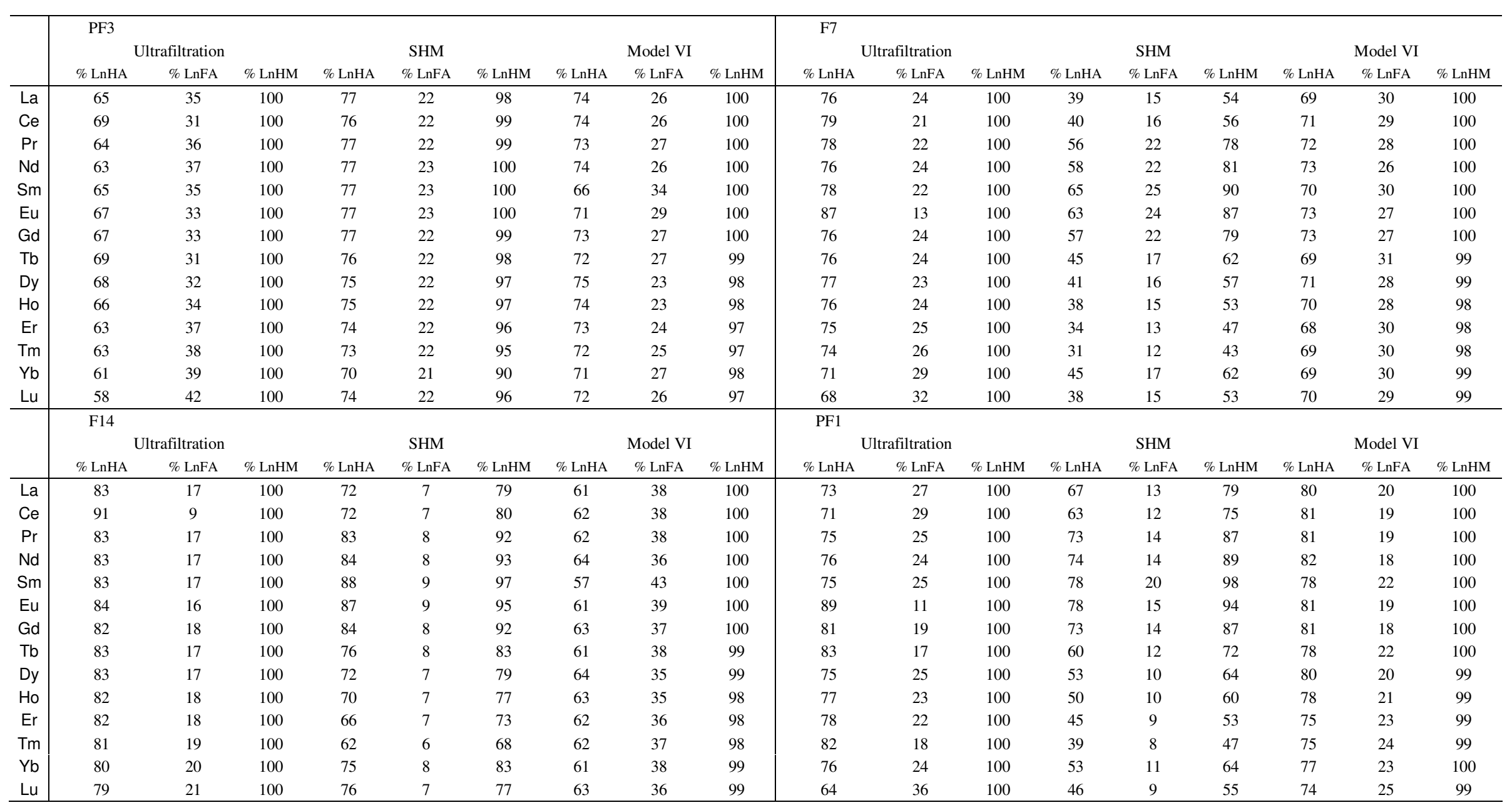

Table 6. 


\begin{tabular}{lcccccc}
\hline & \multicolumn{2}{c}{$\%$ Fe-HM } & \multicolumn{2}{c}{$\%$ Al-HM } & \multicolumn{2}{c}{$\%$ Ca-HM } \\
pH & Model VI & SHM & Model VI & SHM & Model VI & SHM \\
\hline 3 & 10 & 31 & 19 & 1 & 0 & 0 \\
3.5 & 15 & 41 & 38 & 2 & 0 & 0 \\
4 & 16 & 45 & 56 & 7 & 1 & 0 \\
4.5 & 15 & 42 & 71 & 26 & 1 & 0 \\
5 & 13 & 34 & 81 & 64 & 1 & 0 \\
5.5 & 12 & 25 & 82 & 85 & 1 & 1 \\
6 & 10 & 16 & 75 & 90 & 2 & 1 \\
6.5 & 10 & 9 & 53 & 85 & 2 & 1 \\
7 & 10 & 5 & 17 & 62 & 2 & 1 \\
7.5 & 9 & 3 & 2 & 27 & 2 & 1 \\
8 & 7 & 2 & 0 & 8 & 2 & 2 \\
8.5 & 4 & 1 & 0 & 2 & 3 & 2 \\
9 & 2 & 0 & 0 & 0 & 3 & 2 \\
9.5 & 1 & 0 & 0 & 0 & 3 & 2 \\
\hline
\end{tabular}

Table 7. 


\begin{tabular}{c|ccc|ccc}
\hline & $\begin{array}{c}\text { Ultrafiltration } \\
\text { \% LnHM }\end{array}$ & $\begin{array}{c}\text { Mengong } \\
\text { Model VI }\end{array}$ & $\begin{array}{c}\text { SHM } \\
\% \text { LnHM }\end{array}$ & $\begin{array}{c}\text { Ultrafiltration } \\
\text { \% LnHM }\end{array}$ & $\begin{array}{c}\text { Mar2 } \\
\text { M LnHM }\end{array}$ & $\begin{array}{c}\text { SHM } \\
\% \text { LnHM }\end{array}$ \\
\hline $\mathrm{La}$ & 86 & 98 & 85 & 94 & 100 & 99 \\
$\mathrm{Ce}$ & 86 & 98 & 86 & 94 & 100 & 99 \\
$\mathrm{Pr}$ & 87 & 99 & 92 & 96 & 100 & 99 \\
$\mathrm{Nd}$ & 86 & 99 & 94 & 95 & 100 & 99 \\
$\mathrm{Sm}$ & 100 & 100 & 93 & 100 & 100 & 100 \\
$\mathrm{Gd}$ & 100 & 99 & 94 & 100 & 100 & 99 \\
$\mathrm{~Tb}$ & 100 & 98 & 75 & 100 & 100 & 98 \\
$\mathrm{Dy}$ & 100 & 97 & 71 & 100 & 100 & 98 \\
$\mathrm{Ho}$ & 100 & 96 & 69 & 100 & 100 & 98 \\
$\mathrm{Er}$ & 69 & 95 & 66 & 100 & 100 & 98 \\
$\mathrm{Tm}$ & 100 & 96 & 64 & 100 & 100 & 98 \\
$\mathrm{Yb}$ & 100 & 98 & 78 & 100 & 100 & 99 \\
$\mathrm{Lu}$ & 100 & 97 & 71 & 100 & 100 & 98 \\
\hline
\end{tabular}

Table 8. 


\begin{tabular}{|c|c|c|}
\hline Parameter & Description & Values \\
\hline $\mathrm{n}_{\mathrm{A}}$ & Amount of type-A sites $\left(\mathrm{mol} \mathrm{g}^{-1}\right)$ & $4.810^{-3}(\mathrm{FA}), 3.310^{-3}(\mathrm{HA})$ \\
\hline $\mathrm{n}_{\mathrm{B}}$ & Amount of type-B sites $\left(\mathrm{mol} \mathrm{g}^{-1}\right)$ & $0.5 \times \mathrm{n}_{\mathrm{A}}$ \\
\hline $\mathrm{pK}_{\mathrm{A}}$ & Intrinsic proton dissociation constant for type-A sites & 3.2 (FA), 4.1 (HA) \\
\hline $\mathrm{pK}_{\mathrm{B}}$ & Intrinsic proton dissociation constant for type-B sites & 9.4 (FA), 8.8 (HA) \\
\hline$\Delta \mathrm{pK}_{\mathrm{A}}$ & Distribution term that modifies $\mathrm{pK}_{\mathrm{A}}$ & 3.3 (FA), 2.1 (HA) \\
\hline$\Delta \mathrm{pK}_{\mathrm{B}}$ & Distribution term that modifies $\mathrm{pK}_{\mathrm{B}}$ & 4.9 (FA), 3.6 (HA) \\
\hline $\log \mathrm{K}_{\mathrm{MA}}$ & Intrinsic equilibrium constant for metal binding at type-A sites & Fitted from experimental data \\
\hline $\log K_{M B}$ & Intrinsic equilibrium constant for metal binding at type-B sites & $3.39 \log \mathrm{K}_{\mathrm{MA}}-1.15$ \\
\hline$\Delta \mathrm{LK}_{1}$ & Distribution term that modifies $\log \mathrm{K}_{\mathrm{MA}}$ & 2.8 (REE) \\
\hline$\Delta \mathrm{LK}_{2}$ & Distribution term that modifies the strength of bidentate and tridentate sites & $0.55 \log \mathrm{K}_{\mathrm{NH} 3}=0.29$ (REE) \\
\hline $\mathrm{P}$ & Electrostatic parameter & $-115(\mathrm{FA}),-330(\mathrm{HA})$ \\
\hline $\mathrm{K}_{\mathrm{sel}}$ & Selectivity coefficient for counterion accumulation & 1 \\
\hline$f_{\mathrm{prB}}$ & Fraction of proton sites that can form bidentate sites & Calculated from geometry \\
\hline$f_{\mathrm{prT}}$ & Fraction of proton sites that can form tridentate sites & Calculated from geometry \\
\hline $\mathrm{M}$ & Molecular weight & 1500 (FA), 15000 (HA) \\
\hline $\mathrm{r}$ & Molecular radius & $0.8 \mathrm{~nm}(\mathrm{FA}), 1.72 \mathrm{~nm}(\mathrm{HA})$ \\
\hline
\end{tabular}

Table EA1. 


\begin{tabular}{lll}
\hline Parameter & Description & Values \\
\hline $\mathrm{n}_{\mathrm{A}}$ & Amount of type-A sites $\left(\mathrm{mol} \mathrm{g}^{-1}\right)$ & $5.410^{-3}(\mathrm{FA}), 3.5510^{-3}(\mathrm{HA})$ \\
$\mathrm{n}_{\mathrm{B}}$ & Amount of type-B sites $\left(\mathrm{mol} \mathrm{g}^{-1}\right)$ & $1.6210^{-3}(\mathrm{FA}), 1.7810^{-3}(\mathrm{HA})$ \\
$\log \mathrm{K}_{\mathrm{A}}$ & Intrinsic proton dissociation constant for type-A sites & $-3.51(\mathrm{FA}),-4.13(\mathrm{HA})$ \\
$\log \mathrm{K}_{\mathrm{B}}$ & Intrinsic proton dissociation constant for type-B sites & $-8.81(\mathrm{FA}),-8.99(\mathrm{HA})$ \\
$\Delta \mathrm{pK}_{\mathrm{A}}$ & Distribution term that modifies log $\mathrm{K}_{\mathrm{A}}$ & $3.48(\mathrm{FA}), 3.03(\mathrm{HA})$ \\
$\Delta \mathrm{pK}_{\mathrm{B}}$ & Distribution term that modifies log $\mathrm{K}_{\mathrm{B}}$ & $2.49(\mathrm{FA}), 3.03(\mathrm{HA})$ \\
$\log \mathrm{K}_{\mathrm{Mm}}$ & Intrinsic equilibrium constant for monodentate complexation of metal M & Fitted from experimental data \\
$\log \mathrm{K}_{\mathrm{Mb}}$ & Intrinsic equilibrium constant for bidentate complexation of metal M & Fitted from experimental data \\
$\Delta \mathrm{LK}_{2}$ & Distribution term that modifies the strength of complexation sites & 1.3 (REE) \\
$\mathrm{r}$ & Molecular radius & 0.75 nm (FA), $1.8 \mathrm{~nm}(\mathrm{HA})$ \\
$\mathrm{C}$ & Stern layer capacitance & $2 \mathrm{~F} \mathrm{~m} \mathrm{~m}^{-2}$ \\
$\mathrm{~N}_{\mathrm{s}}$ & Site density of HS functional groups & 1.2 sites nm \\
$\mathrm{A}_{\mathrm{s}}$ & Specific surface area of HS & Calculated from geometry using r and N \\
$\mathrm{g}_{\mathrm{f}}$ & Gel fraction parameters & $0.72(\mathrm{FA}) 0.78(\mathrm{HA})$ \\
$\mathrm{K}_{\mathrm{C}}$ & Intrinsic equilibrium constant for accumulation of screening counterions & universal value: $10^{0.8}$ \\
\hline
\end{tabular}

Table EA2. 


\begin{tabular}{ccccc}
\hline & PF1 & PF3 & F7 & F14 \\
\hline $\mathrm{T}\left({ }^{\circ} \mathrm{C}\right)$ & 10.6 & 10.7 & 10.6 & 10.4 \\
$\mathrm{pH}$ & 7.08 & 6.93 & 6.19 & 6.4 \\
$\mathrm{Cl}$ & 1340.00 & 1040.00 & 1949.99 & 1490.00 \\
$\mathrm{SO} 4$ & 106.56 & 89.23 & 642.56 & 364.65 \\
$\mathrm{NO} 3$ & 33.72 & 740.89 & 9.19 & 6.93 \\
$\mathrm{DOC}$ & 17.25 & 7.66 & 11.12 & 21.49 \\
$\mathrm{Na}$ & 628.10 & 555.03 & 1526.33 & 868.21 \\
$\mathrm{Mg}$ & 737.71 & 513.06 & 459.99 & 266.45 \\
$\mathrm{Al}$ & 3.97 & 2.71 & 0.59 & 3.97 \\
$\mathrm{~K}$ & 12.58 & 8.21 & 14.02 & 7.70 \\
$\mathrm{Ca}$ & 213.75 & 161.03 & 722.55 & 609.78 \\
$\mathrm{Fe}$ & 17.10 & 1.77 & 25.62 & 44.08 \\
$\mathrm{Mn}$ & 0.56 & 0.18 & 21.72 & 9.32 \\
$\mathrm{La}$ & 1.27 & 5.79 & 3.73 & 10.00 \\
$\mathrm{Ce}$ & 2.60 & 13.48 & 9.27 & 22.16 \\
$\mathrm{Pr}$ & 0.39 & 1.81 & 1.24 & 3.02 \\
$\mathrm{Nd}$ & 1.66 & 7.66 & 5.63 & 12.67 \\
$\mathrm{Sm}$ & 0.33 & 1.29 & 1.34 & 2.93 \\
$\mathrm{Eu}$ & 0.07 & 0.24 & 0.27 & 0.61 \\
$\mathrm{Gd}$ & 0.26 & 0.86 & 1.31 & 2.73 \\
$\mathrm{~Tb}$ & 0.03 & 0.08 & 0.18 & 0.38 \\
$\mathrm{Dy}$ & 0.16 & 0.41 & 1.12 & 2.23 \\
$\mathrm{Ho}$ & 0.03 & 0.08 & 0.24 & 0.43 \\
$\mathrm{Er}$ & 0.09 & 0.21 & 0.77 & 1.22 \\
$\mathrm{Tm}$ & 0.01 & 0.03 & 0.11 & 0.17 \\
$\mathrm{Yb}$ & 0.09 & 0.18 & 0.71 & 1.05 \\
$\mathrm{Lu}$ & 0.02 & 0.03 & 0.12 & 0.16 \\
$\mathrm{Alkalinity}$ & 1867 & 385 & 1318 & 623 \\
\hline & & & &
\end{tabular}

Table EA3. 


\begin{tabular}{|c|c|c|c|c|c|c|c|c|c|c|c|c|c|c|c|c|}
\hline & \multicolumn{4}{|c|}{ PF3 } & \multicolumn{4}{|c|}{ F7 } & \multicolumn{4}{|c|}{$\mathrm{F} 14$} & \multicolumn{4}{|c|}{ PF1 } \\
\hline & $0.2 \mu \mathrm{m}$ & $30 \mathrm{kDa}$ & $10 \mathrm{kDa}$ & $5 \mathrm{kDa}$ & $0.2 \mu \mathrm{m}$ & $30 \mathrm{kDa}$ & $10 \mathrm{kDa}$ & $5 \mathrm{kDa}$ & $0.2 \mu \mathrm{m}$ & $30 \mathrm{kDa}$ & $10 \mathrm{kDa}$ & $5 \mathrm{kDa}$ & $0.2 \mu \mathrm{m}$ & $30 \mathrm{kDa}$ & $10 \mathrm{kDa}$ & $5 \mathrm{kDa}$ \\
\hline $\mathrm{La}$ & 5.79 & 4.14 & 3.12 & 2.01 & 3.73 & 1.31 & 1.09 & 0.60 & 10.00 & 2.97 & 1.77 & 0.79 & 1.27 & 0.21 & 0.15 & 0.08 \\
\hline $\mathrm{Ce}$ & 13.48 & 9.63 & 7.22 & 4.20 & 9.27 & 3.08 & 2.52 & 1.30 & 22.16 & 6.27 & 3.55 & 0.95 & 2.60 & 0.42 & 0.32 & 0.17 \\
\hline $\operatorname{Pr}$ & 1.81 & 1.31 & 0.99 & 0.66 & 1.24 & 0.44 & 0.36 & 0.19 & 3.02 & 0.93 & 0.54 & 0.24 & 0.39 & 0.08 & 0.05 & 0.03 \\
\hline $\mathrm{Nd}$ & 7.66 & 5.73 & 4.33 & 2.85 & 5.63 & 2.19 & 1.81 & 1.00 & 12.67 & 4.16 & 2.50 & 1.13 & 1.66 & 0.36 & 0.29 & 0.12 \\
\hline $\mathrm{Sm}$ & 1.29 & 0.94 & 0.68 & 0.46 & 1.34 & 0.56 & 0.45 & 0.24 & 2.93 & 1.01 & 0.61 & 0.27 & 0.33 & 0.09 & 0.07 & 0.03 \\
\hline $\mathrm{Eu}$ & 0.24 & 0.17 & 0.13 & 0.08 & 0.27 & 0.11 & 0.09 & 0.03 & 0.61 & 0.21 & 0.12 & 0.05 & 0.07 & 0.02 & 0.02 & 0.00 \\
\hline $\mathrm{Gd}$ & 0.86 & 0.61 & 0.46 & 0.29 & 1.31 & 0.60 & 0.48 & 0.27 & 2.73 & 1.04 & 0.62 & 0.28 & 0.26 & 0.08 & 0.06 & 0.02 \\
\hline $\mathrm{Tb}$ & 0.08 & 0.06 & 0.04 & 0.03 & 0.18 & 0.08 & 0.06 & 0.03 & 0.38 & 0.15 & 0.09 & 0.04 & 0.03 & 0.01 & 0.01 & 0.00 \\
\hline Dy & 0.41 & 0.30 & 0.22 & 0.13 & 1.12 & 0.52 & 0.40 & 0.23 & 2.23 & 0.87 & 0.54 & 0.24 & 0.16 & 0.05 & 0.04 & 0.02 \\
\hline Ho & 0.08 & 0.06 & 0.04 & 0.03 & 0.24 & 0.12 & 0.10 & 0.06 & 0.43 & 0.19 & 0.12 & 0.05 & 0.03 & 0.01 & 0.01 & 0.00 \\
\hline $\mathrm{Er}$ & 0.21 & 0.16 & 0.12 & 0.08 & 0.77 & 0.40 & 0.33 & 0.19 & 1.22 & 0.55 & 0.37 & 0.16 & 0.09 & 0.04 & 0.03 & 0.01 \\
\hline $\mathrm{Tm}$ & 0.03 & 0.02 & 0.02 & 0.01 & 0.11 & 0.06 & 0.05 & 0.03 & 0.17 & 0.08 & 0.05 & 0.02 & 0.01 & 0.01 & 0.00 & 0.00 \\
\hline $\mathrm{Yb}$ & 0.18 & 0.14 & 0.11 & 0.07 & 0.71 & 0.42 & 0.35 & 0.21 & 1.05 & 0.53 & 0.36 & 0.17 & 0.09 & 0.04 & 0.03 & 0.01 \\
\hline $\mathrm{Lu}$ & 0.03 & 0.03 & 0.02 & 0.01 & 0.12 & 0.08 & 0.06 & 0.04 & 0.16 & 0.09 & 0.06 & 0.03 & 0.02 & 0.01 & 0.01 & 0.00 \\
\hline$\Sigma \mathrm{REE}$ & 32.15 & 23.30 & 17.48 & 10.89 & 26.04 & 9.97 & 8.15 & 4.41 & 59.78 & 19.04 & 11.29 & 4.44 & 7.00 & 1.41 & 1.09 & 0.52 \\
\hline DOC & 7.66 & 6.66 & 5.66 & 4.97 & 11.12 & 8.14 & 7.93 & 6.58 & 21.49 & 16.28 & 14.38 & 10.55 & 17.25 & 15.73 & 14.27 & 13.48 \\
\hline $\mathrm{Al}$ & 2.69 & 0.67 & 0.57 & 0.39 & 0.58 & 0.28 & 0.22 & 0.13 & 3.97 & 1.58 & 1.16 & 0.60 & 0.93 & 0.43 & 0.38 & 0.24 \\
\hline Mn & 0.18 & 0.16 & 0.16 & 0.05 & 21.72 & 22.88 & 22.56 & 20.99 & 9.32 & 7.77 & 7.72 & 0.24 & 0.56 & 0.46 & 0.46 & 0.18 \\
\hline $\mathrm{Fe}$ & 1.77 & 0.21 & 0.48 & 0.00 & 25.62 & 0.97 & 0.48 & 0.11 & 44.08 & 5.19 & 1.36 & 0.41 & 17.10 & 0.63 & 0.41 & 0.11 \\
\hline
\end{tabular}

Table EA4. 

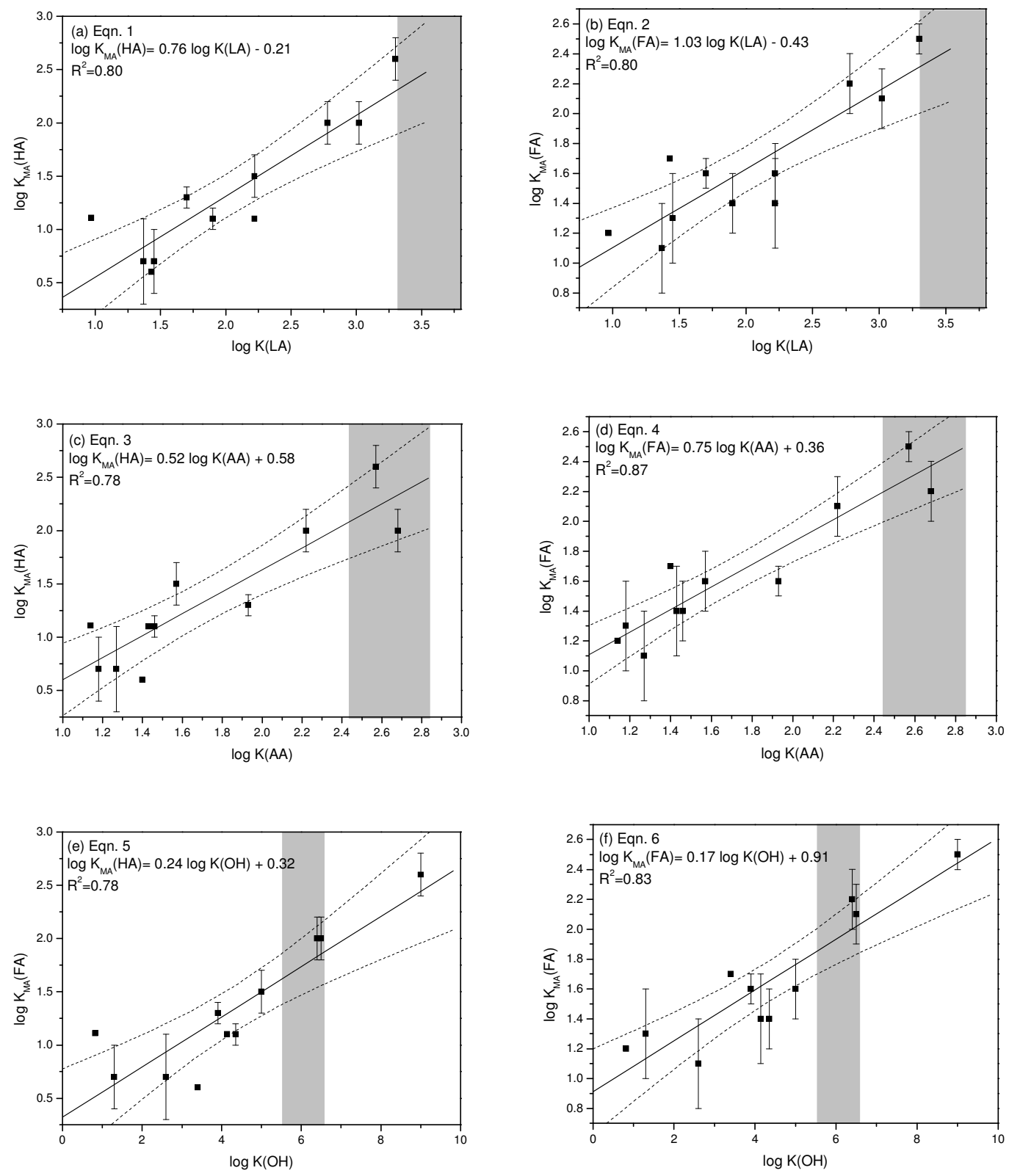

Fig. 1. 

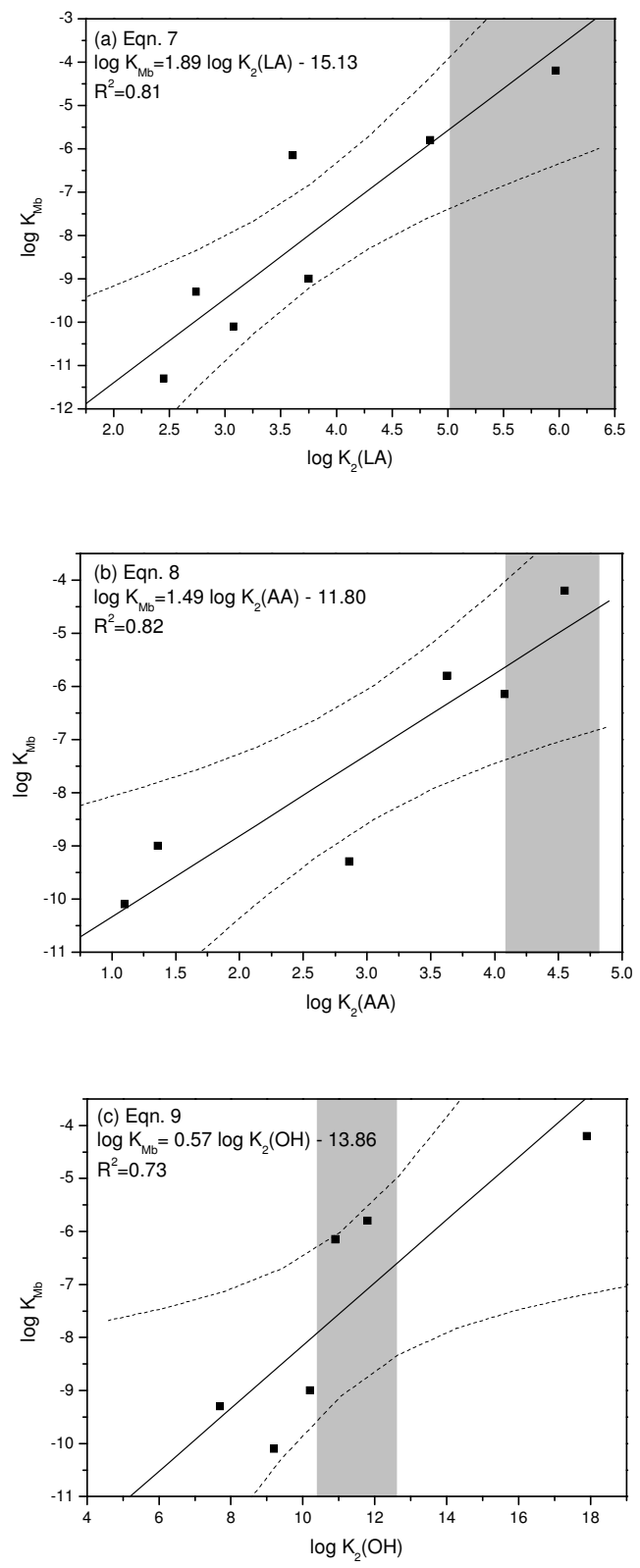

Fig. 2. 

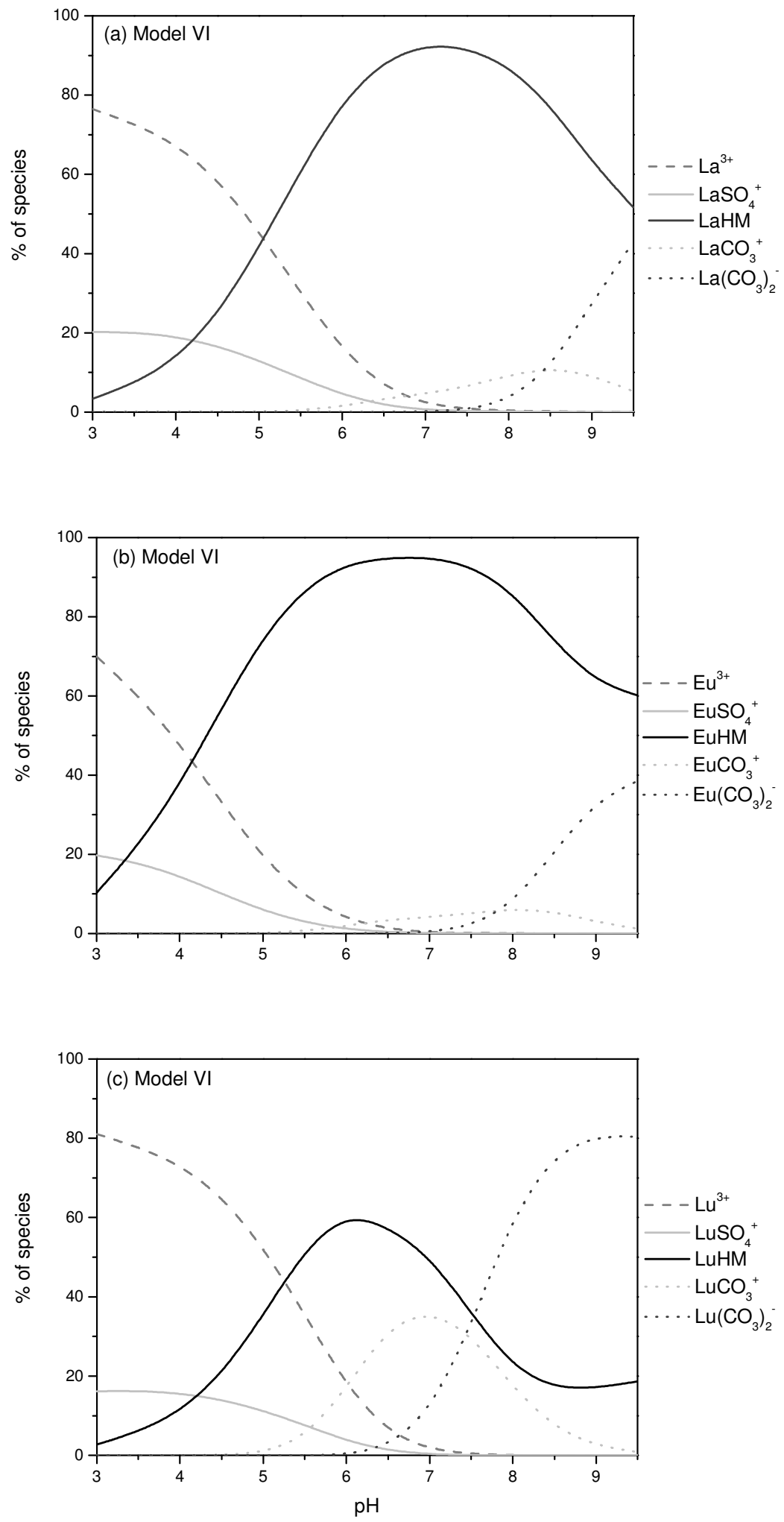

Fig. 3. 

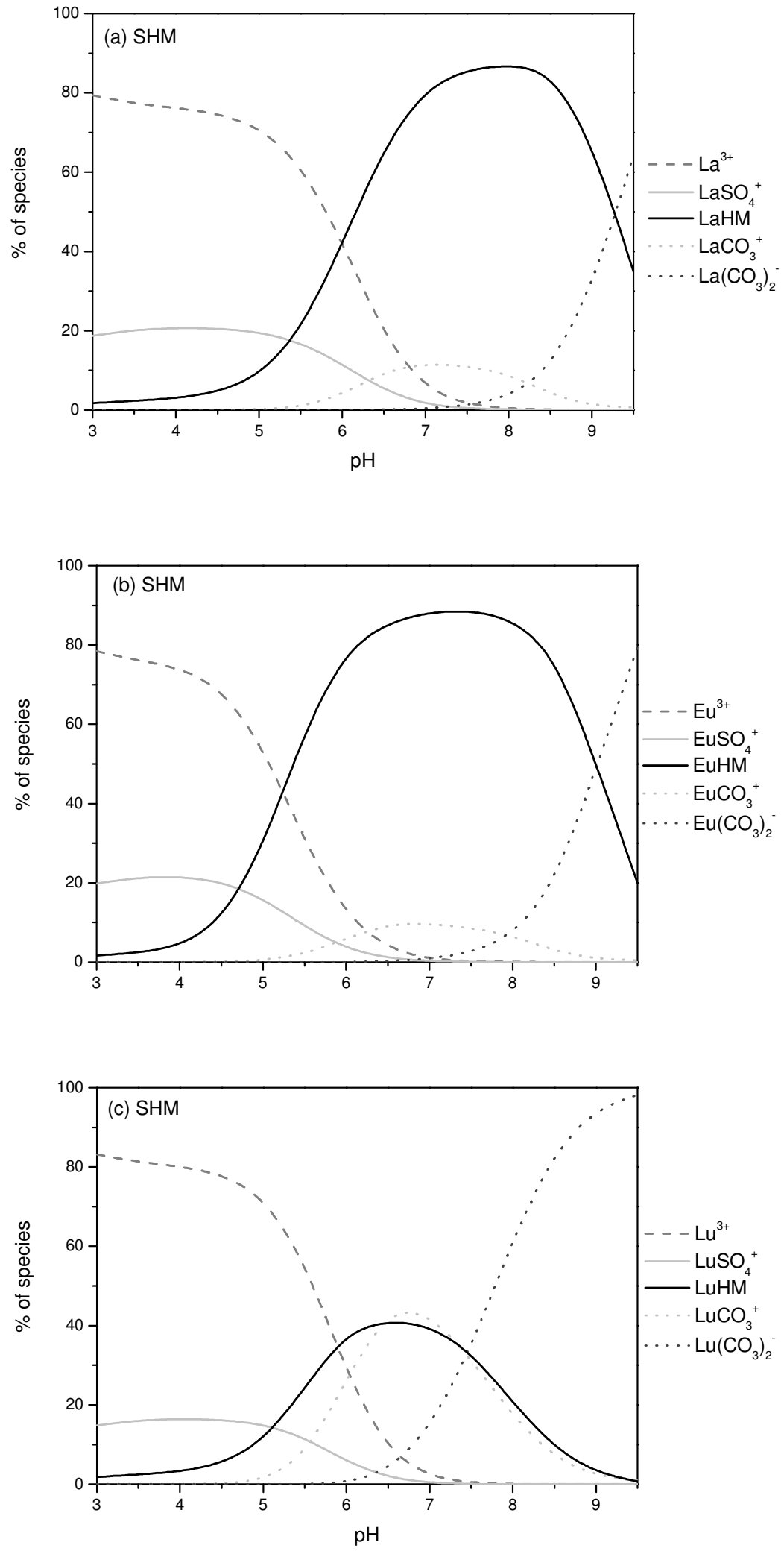

Fig. 4. 

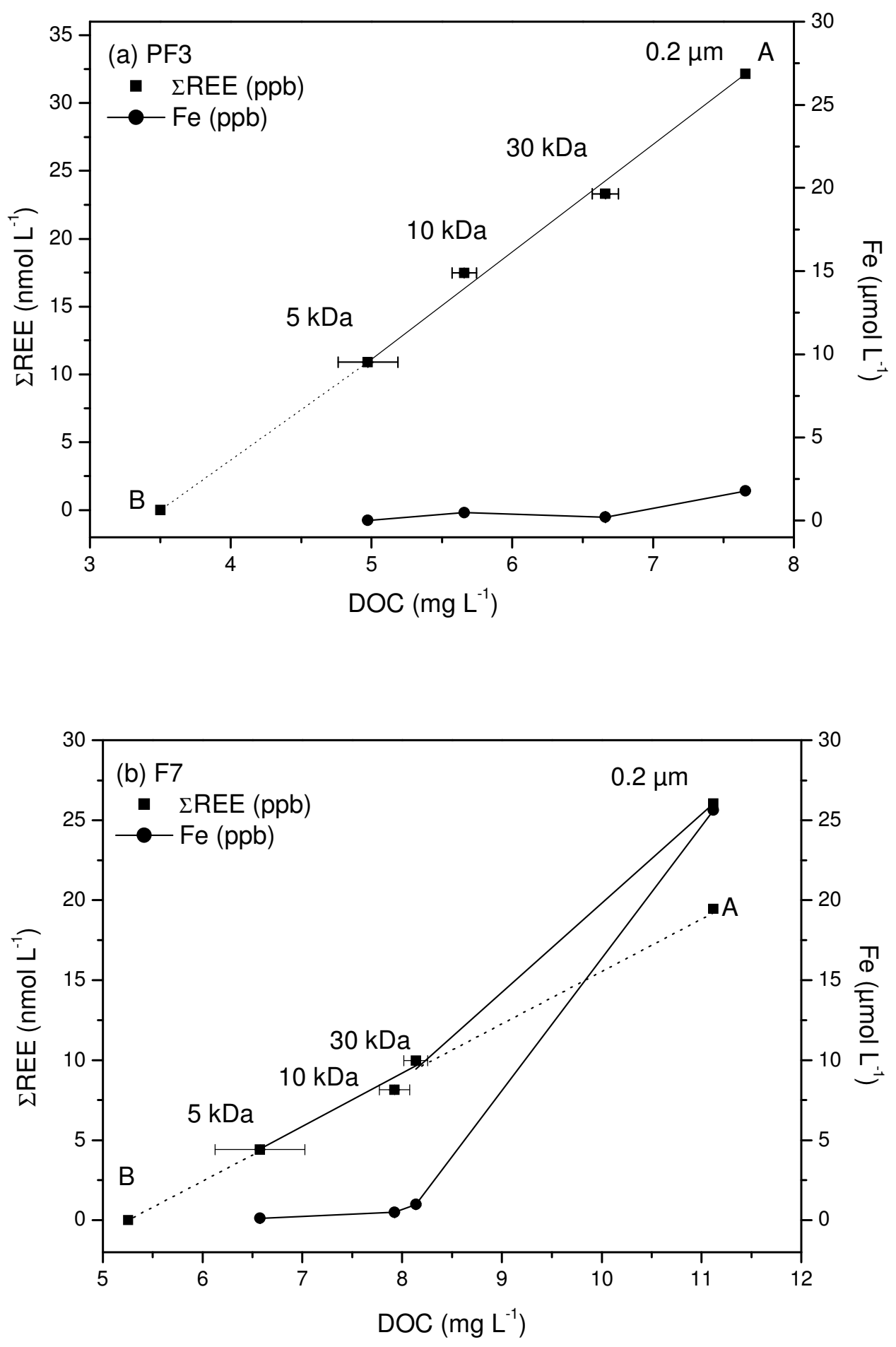

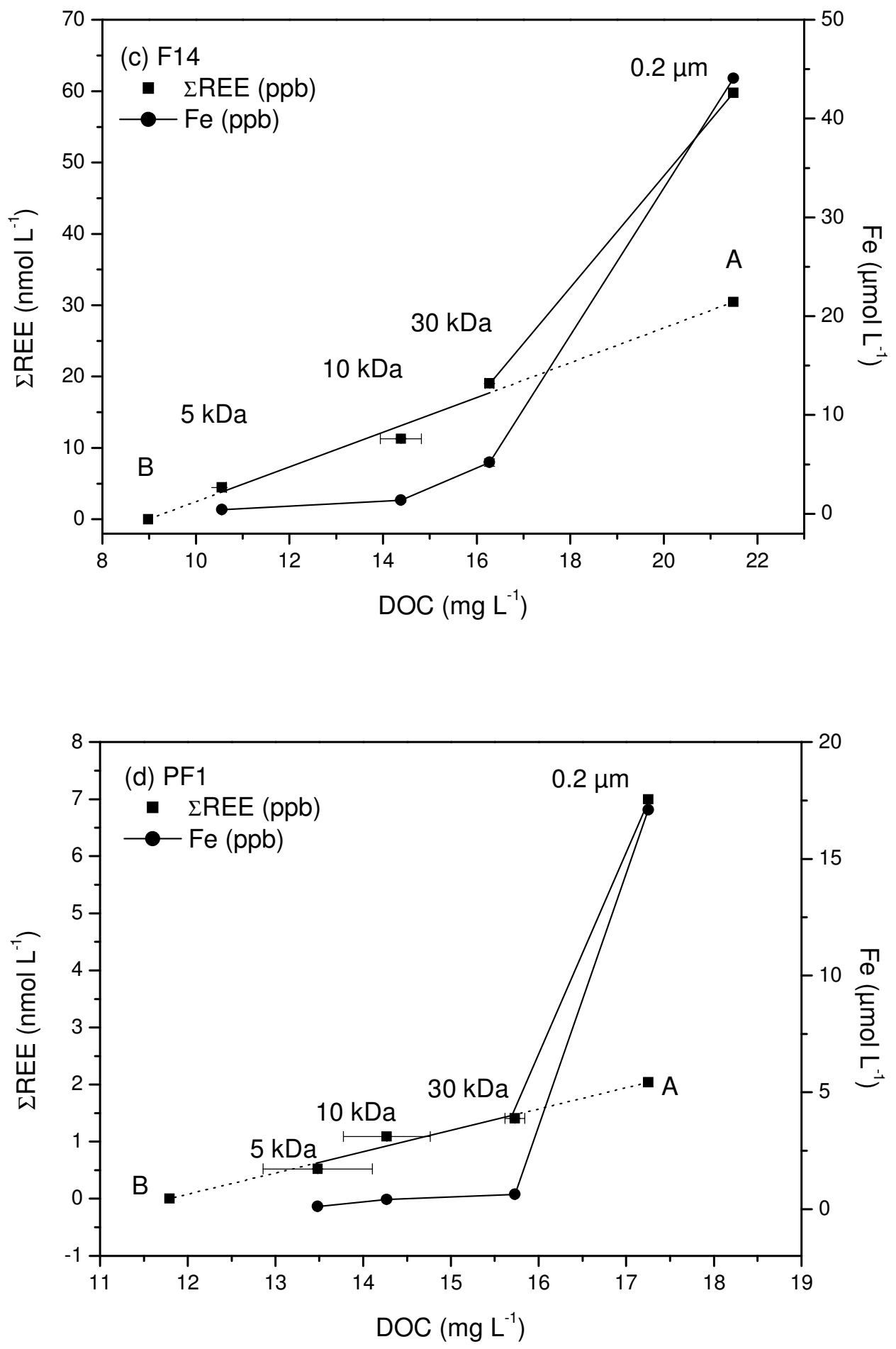

Fig. 5. 


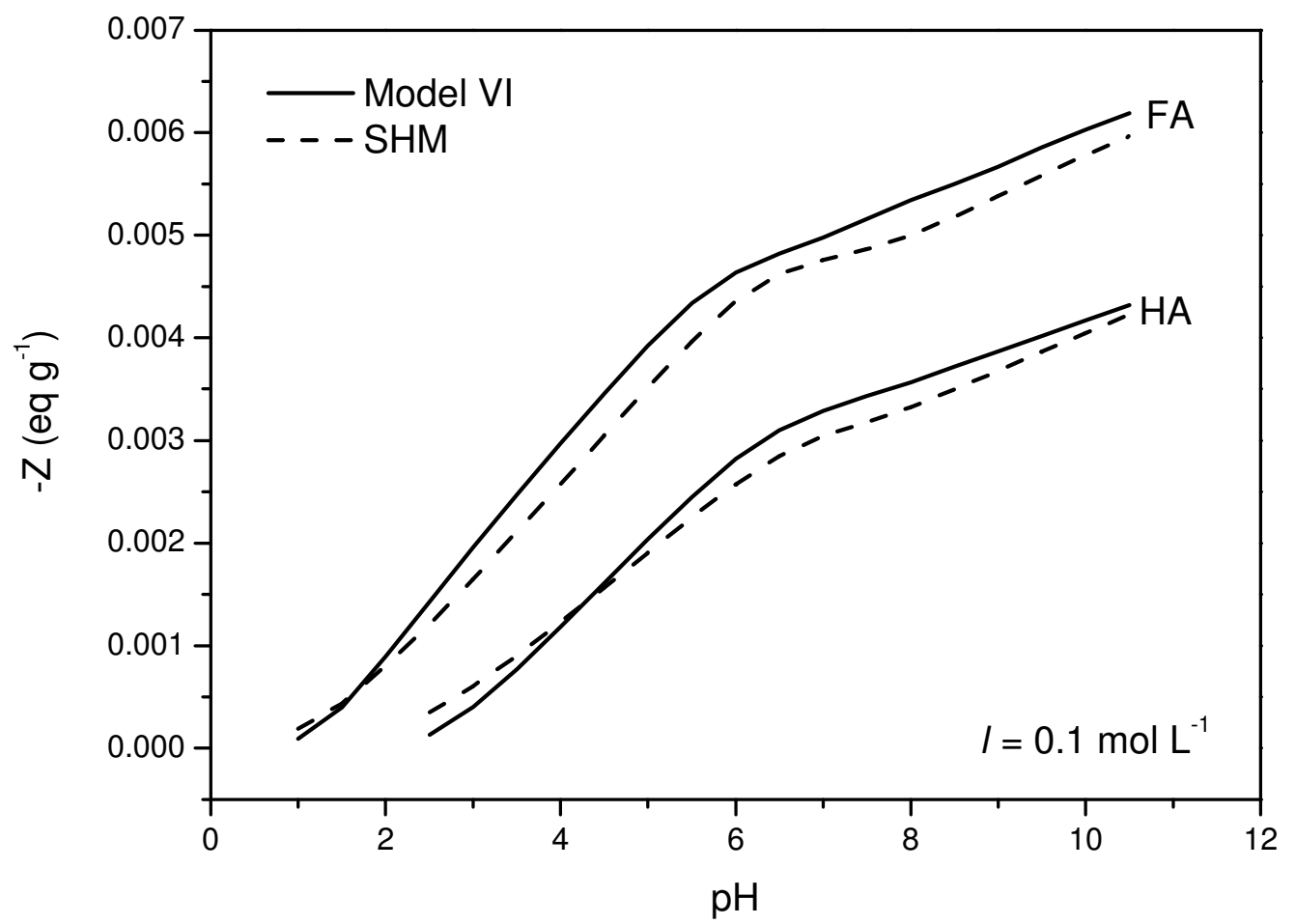

Fig. 6. 

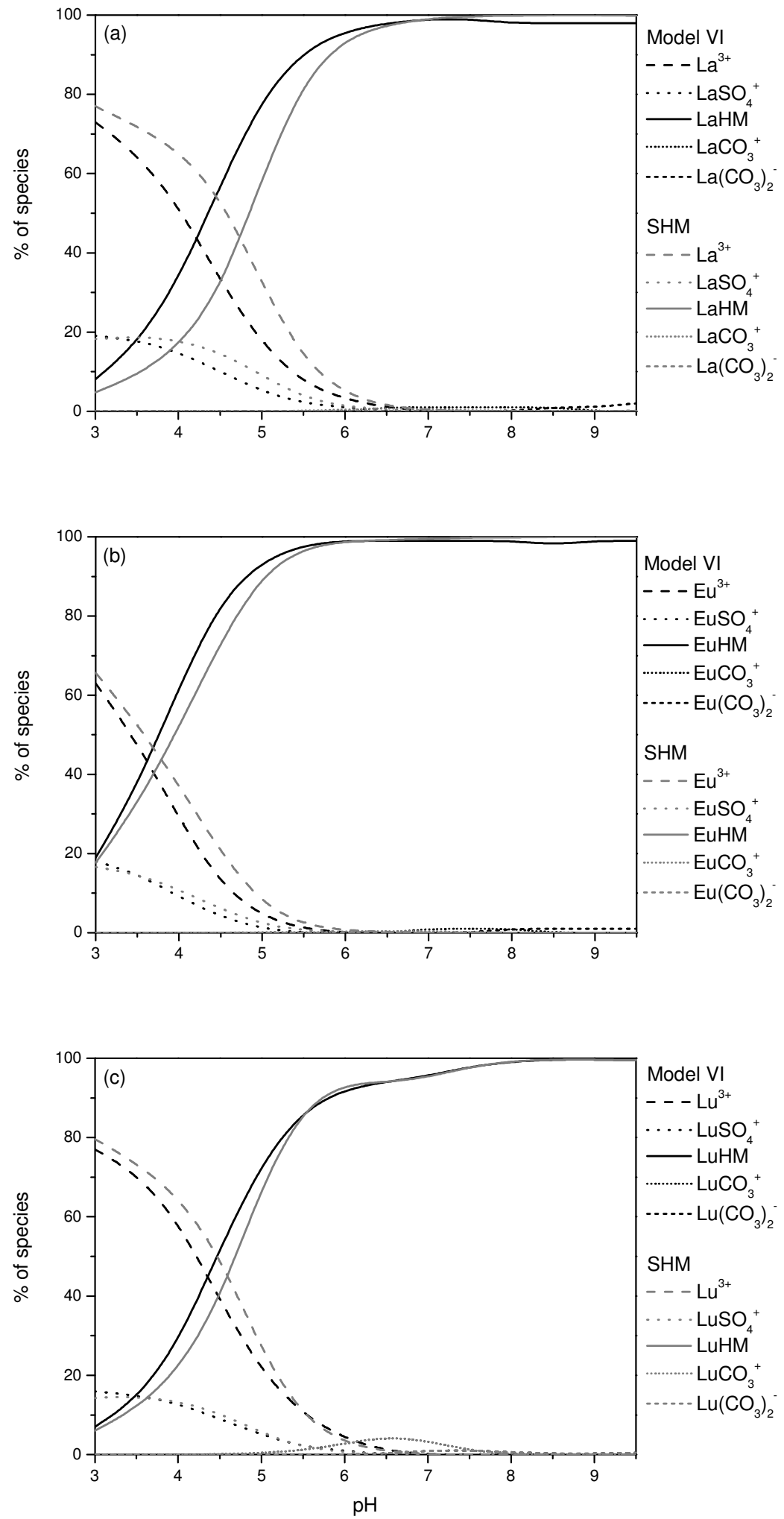

Fig. 7. 